CIGÜELA, Javier "Culpabilidad, identidad y organización colectiva".

Polít. crim. Vol. 12, No 24 (Diciembre 2017), Art. 7, pp. 908-931.

[http://www.politicacriminal.cl/Vol_12/n_24/Vol12N24A7.pdf]

\title{
Culpabilidad, identidad y organización colectiva
}

\section{Guilt, Identity and Collective Organization}

\author{
Dr. Javier Cigüela Sola* \\ Universitat Abat Oliba / Universitat Oberta de Catalunya \\ jciguelas@uao.es / jciguela@uoc.edu
}

\begin{abstract}
Resumen
La capacidad que tienen las organizaciones de condicionar las disposiciones y las acciones de sus miembros es ya un fenómeno indiscutido. El debate -centenario y todavía muy vivo- es si esa influencia puede reconducirse a categorías jurídico-penales. La tesis central del presente artículo es que la responsabilidad que tenga la organización por sus defectos organizativos no puede integrarse en el concepto de culpabilidad, pues aquélla carece de las condiciones de identidad necesarias para manifestar un posicionamiento personal frente a la norma penal. Aquello que la organización "es" -su filosofía o cultura corporativa- y aquello que "hace" - su correcta o incorrecta organización- depende de otros, y no es posible hablar de una culpabilidad propia fundada en prestaciones que la organización recibe de terceros.
\end{abstract}

Palabras clave: culpabilidad, persona jurídica, identidad penal, reproche, organización

\begin{abstract}
The influence of organizations on its member's actions and dispositions is nowadays an undisputed phenomenon. The debate -centenarian and still very alive- is whether this influence can be redirected to criminal law categories. The central thesis of this article is that the responsibility that the organization has for its organizational defects cannot be integrated into the concept of guilt, since it lacks the necessary identity conditions to commit a personal offence against the penal norm. What the organization "is" -its corporate philosophy or culture- and what it "does" -its correct or incorrect organizationdepends on others, and it is not possible to speak of personal culpability based on benefits that the organization receives from others.
\end{abstract}

Key words: guilt, legal person, penal identity, reproach, organization

\section{El problema: el componente estructural de la delincuencia en organizaciones}

La pregunta por la culpabilidad colectiva resurge siempre en momentos históricos en los que determinados fenómenos criminales no parecen poder explicarse solamente desde la perspectiva individual -la disposición o motivación de los individuos-, requiriéndose también una explicación estructural o sistémica, esto es, que tenga en cuenta el modo en 
CIGÜELA, Javier "Culpabilidad, identidad y organización colectiva".

que determinados contextos de interacción social favorecen el comportamiento criminal. Así sucedió en relación a la violencia política ocurrida durante la primera mitad del siglo XX y los totalitarismos, donde la culpabilidad colectiva apareció como una posible explicación o respuesta a los crímenes en masa perpetrados en el seno de diversas estructuras de Estado ${ }^{1}$ y así viene sucediendo con motivo de la crisis económica en el siglo XXI, la cual estaría conectada a una serie de fenómenos criminales de carácter económicopolítico, como el fraude bancario o la corrupción, que no se dejan comprender adecuadamente sin tener en cuenta el estado defectuoso de determinadas organizaciones sean empresas, partidos políticos o la propia administración ${ }^{2}$. Ante la percepción de que este tipo de criminalidad tiene en buena medida una explicación sistémica o estructural, parece necesario preguntarse si hay que articular responsabilidades que operen también en niveles supra-individuales.

Sobre la base de la necesidad de prevenir la existencia de organizaciones donde se incentiva, favorece u oculta el delito, la dogmática jurídico-penal ha ideado básicamente dos modelos de culpabilidad para organizaciones, por todos conocidos: el modelo de culpabilidad por el hecho propio y el modelo de culpabilidad por transferencia. Con independencia de que otros conceptos y formas de responsabilidad sean posibles $-\mathrm{mi}$ propuesta es la de un modelo de responsabilidad estructural, disociado de la idea de culpabilidad y de reproche ${ }^{3}$-, el principal obstáculo al que se enfrentan los modelos de culpabilidad colectiva se halla en la identidad de la propia organización a la que se querría atribuir el hecho delictivo. A demostrar dicha idea se dedica el presente artículo, en primer lugar, analizando los dos principales paradigmas teóricos de los que se sirven sus defensores (II); y, en segundo lugar, argumentando qué cualquier intento de culpabilizar a la organización por los delitos ocurridos en su seno choca con déficits de identidad que son para ella constitutivos (III).

\section{Fundamentaciones de la culpabilidad colectiva: el paradigma filosófico- intencional y el sociológico-sistémico}

En lo que al pensamiento contemporáneo respecta, las fundamentaciones de la culpabilidad colectiva podrían reconducirse a dos grandes paradigmas: el «paradigma filosóficointencional», desarrollado por autores como French o Pettit y muy presente en el mundo

\footnotetext{
* El presente artículo fue publicado en la revista Goltdammer's Archiv für Strafrecht (GA) 10/2016, pp. 625638, excepto el punto II, que es inédito.

${ }^{1}$ Cfr. JASPERS, Karl, Die Schuldfrage, Heidelberg: Lambert Schneider, 1946; ROTHENPIELER, Friedrich Wilhelm, Der Gedanke einer Kollektivschuld in juristischer Sicht, Berlin: Duncker \& Humblot, 1982; ARENDT, Hannah, Eichmann en Jerusalén, Barcelona: DeBolsillo, 2010. En la ciencia penal: OSTERMEYER, Helmut, "Kollektivschuld im Strafrecht", ZRP, Heft 4/1971, pp. 76 y ss.; ROTH, Andreas, Kollektive Gewalt und Strafrecht, Berlin: Erich Schmidt Verlag, 1989; JÄGER, Herbert, Makrokriminalität, Frankfurt am Main: Suhrkamp Verlag,1989; LAMPE, "Systemunrecht und Unrechtssysteme", ZStW 106 (1994), 700 y ss., 709.

${ }^{2}$ Una panorámica general, desde ópticas diversas: JURKIEWICZ, Carole L. (Ed.), The Foundations of Organizational Evil, New York: M.E. Sharpe, 2012.

${ }^{3}$ CIGÜELA SOLA, Javier, La culpabilidad colectiva en el derecho penal. Crítica y propuesta de una responsabilidad estructural de la empresa, Madrid: Marcial Pons, 2015, Parte III; EL MISMO, "El injusto estructural de la organización: aproximación al fundamento de la sanción a la persona jurídica", InDret $1 / 2015$.
} 
Polít. crim. Vol. 12, No 24 (Diciembre 2017), Art. 7, pp. 908-931.

[http://www.politicacriminal.cl/Vol_12/n_24/Vol12N24A7.pdf]

anglosajón $^{4}$; y el «paradigma sociológico-funcional», desarrollado por autores como Bottke, Lampe, S. Bacigalupo o Gómez-Jara, a partir de los presupuestos de la teoría de sistemas de Luhmann ${ }^{5}$. Ambos planteamientos tratan de justificar que esa influencia estructural es reconducible a una intencionalidad o voluntad colectiva de la propia organización, la cual constituiría un agente moral diferenciado de sus miembros.

El «paradigma filosófico-intencional» extiende el concepto de agencia a los sujetos colectivos por la vía de extender el concepto de intencionalidad. Así, se afirma que en toda organización, por encima de los individuos que la integran, existen un conjunto de reglas y de procesos de decisión que hace que lo que ocurre en la empresa deba ser entendido, no como el resultado de intenciones individuales, sino como la exteriorización de una intencionalidad colectiva $^{6}$. El sistema organizativo, formado por la estructura funcional y la política empresarial, permitiría sintetizar las acciones y decisiones individuales -en palabras de Pettit, "colectivizar la razón"-, dando lugar a un sujeto intencional nuevo, la propia organización, con "deseos y razones para hacer lo que hace"7. Así, cuando los directivos votan en junta, o cuando los empleados venden productos al consumidor, no lo hacen como individuos sino como miembros de una organización con voluntad propia. Manifestación de este fenómeno serían frases como: "Yo no quería, pero era una directiva de la empresa"; u "Ojalá pudiera no hacerlo, pero tengo que cumplir la normativa de la empresa".

Dejando aparte múltiples matices, en el «modelo sociológico-sistémico» esa "vida propia" de la organización es descrita mediante el concepto de autopoiesis: gracias a los procesos de decisión y a la memoria colectiva, la organización se convierte en un sistema autopoiético, con una identidad (descrita como cultura organizativa) propia e independiente de los miembros, capaz de defraudar expectativas normativas y, por tanto, de cuestionar la vigencia del derecho ${ }^{8}$. Lo que ocurre en las organizaciones es entendido como el resultado

\footnotetext{
${ }^{4}$ PETTIT, Phillip, "The reality of group agents", en: MANTZAVINOS, Chrysostomos (Ed.), Philosophy of the Social Sciences, Philosophical Theory and Scientific Practice, Cambridge: Cambridge University Press, 2009, pp. 67 y ss.; FRENCH, Peter A., “The Corporation as a Moral Person”, en: MAY, Larry; HOFFMAN, Stacy (Eds.), Collective Responsibility. Five decades of debate in theoretical and applied ethics, Maryland: Rowman \& Littlefield, 1991, pp. 133 y ss.; EL MISMO, "Integrity, Intentions, And Corporations", Am. Bus. L. J., 34 (1996), pp. 141 y ss.

5 BOTTKE, Wilfried, "Standortvorteil Wirtschaftskriminalrecht: Müssen Unternehmen "strafmündig" werden? Bemerkungen zum Stand des Wirtschaftskriminalrechts in der Bundesrepublik Deutschland", Wistra 1997, pp. 241 y ss.; LAMPE, "Systemunrecht und Unrechtssysteme”, cit. nota no 1, pp. 683 y ss.; GÓMEZJARA, Carlos, Fundamentos modernos de la culpabilidad empresarial, Lima: Ara, 2009, pp. 310 y ss.; BACIGALUPO, Silvina, La responsabilidad penal de las personas jurídicas, Barcelona: Bosch, 1998. Sobre el concepto de organización en la teoría de sistemas: LUHMANN, Niklas, Organisation und Entscheidung, Berlin: Springer-Verlag, 2011; TEUBNER, Günther, "Enterprise Corporatism. New Industrial Policy and the "Essence" of the Legal Person", Am. J. Comp. L. 36 (1988), pp. 130 y ss.

${ }^{6}$ FRENCH, “The Corporation as a Moral Person", cit. nota $\mathrm{n}^{\circ} 4$, pp. 141 y ss. También, ARTAZA, Osvaldo, La empresa como sujeto de imputación de responsabilidad penal, Madrid: Marcial Pons, 2013, pp. 194 y ss., 223 y ss.

${ }^{7}$ FRENCH, “The Corporation as a Moral Person", cit. nota n ${ }^{\circ} 4$, pp. 134 y ss.; PETTIT, “The reality of group agents", cit. nota $\mathrm{n}^{\mathrm{o}} 4$, pp. 70 y ss.

${ }^{8}$ Sobre el carácter autopoiético de la organización: LUHMANN, Organisation und Entscheidung, cit. nota $\mathrm{n}^{\circ}$ 5, pp. 39 y ss. Con matices, desarrollan este patrón argumentativo: BOTTKE, Assoziationsprävention. Zur heutigen Diskussion der Strafzwecke, Berlin: Duncker \& Humblot, 1995; EL MISMO, "Standortvorteil
} 
CIGÜELA, Javier "Culpabilidad, identidad y organización colectiva".

de las necesidades de la propia organización, y el hecho de que las decisiones se presenten como "propias" de los directivos supone simplemente una "mistificación", dirigida a dar una apariencia de racionalidad y controlabilidad a fenómenos que, en realidad, escapan al control individual ${ }^{9}$. En palabras de Luhmann: "el aporte personal al proceso de decisión es, en la praxis, más bien sobrevalorado."

En el fondo de ambos planteamientos hay, además, referencias a la comunicación social, es decir, al modo en que las empresas son percibidas por la sociedad. Así, para French la prueba de que las corporaciones son agentes morales es que en la práctica lingüística les atribuimos razones para hacer lo que hacen; decimos, por ejemplo, que "Samsung ha implementado un compliance para evitar una sanción", siendo ese "para" la prueba, expresada lingüísticamente, de su intencionalidad ${ }^{11}$. En el «paradigma sociológico» el argumento a favor de la culpabilidad colectiva es que las empresas tienen un protagonismo social cada vez mayor, superior incluso al de los individuos, y en esa medida una "defectuosa organización colectiva" cuestiona el orden social - comunica falta de fidelidad al derecho- tanto como un defectuoso comportamiento individual ${ }^{12}$.

Estos modos de convertir a la organización en un sujeto intencional nuevo -y, por tanto, en capaz de culpabilidad- manifiesta de entrada dos problemas. En primer lugar, para afirmar que la organización se transforma en un "sujeto integrado y unitario" capaz de intencionalidad propia es necesario, al mismo tiempo, afirmar que cuando sus miembros actúan por ella lo hacen como autómatas, como "piezas" de una mecánica funcional que son "activadas" cuando hay que ejecutar una decisión colectiva. Así lo expresa claramente French: "el único método para que la corporación alcance sus deseos u objetivos es la activación del personal ("activation of personnel") que ocupa sus diferentes puestos"13.

Wirtschaftskriminalrecht”, cit. nota n ${ }^{\circ}$ 5, pp. 251 y ss.; LAMPE, "Systemunrecht und Unrechtssysteme”, cit. nota $\mathrm{n}^{\circ} 1$, pp. 690 y ss.; BACIGALUPO, La responsabilidad penal de las personas jurídicas, cit. nota $\mathrm{n}^{\circ} 5$, pp. 359 y ss.; GÓMEZ-JARA, Fundamentos modernos de la culpabilidad empresarial, cit. nota ${ }^{\circ}$ 5; HEINE, Günther, Die strafrechtliche Verantwortlichkeit von Unternehmen. Von individuellen Fehlverhalten zu kollektiven Fehlentwicklungen insbesondere bei Großrisiken. Baden-Baden: Nomos, 1995, pp. 79 y ss.

9 LUHMANN, Organisation und Entscheidung, cit. nota $\mathrm{n}^{\circ}$ 5, pp. 135 y ss.; ROTSCH, Thomas, "Unternehmen, Umwelt und Strafrecht- Ätiologie einer Misere (Teil 2)", Wistra 9 (1999), pp. 373 y ss.

${ }^{10}$ LUHMANN, Organisation und Entscheidung, cit. nota $\mathrm{n}^{\circ}$ 5, p. 286.

${ }^{11}$ FRENCH, "The Corporation as a Moral Person", cit. nota $n^{\circ} 4$, p. 142; COLVIN, Eric, "Corporate Personality and Criminal Liability”, Criminal Law Forum 6 (1995), p. 32; también, HIRSCH, Hans Joaquim, "Strafrechtliche Verantwortlichkeit von Unternehmen", ZStW 107 (1995), p. 292. Sobre la argumentación lingüística: LÜBBE, Weyma, Verantwortung in komplexen kulturellen Prozessen, Freiburg/München: Verlag Karl Alber, 1998, pp. 31 y ss.; NEUHÄUSER, Christian, Unternehmen als moralische Akteure, Frankfurt am Main: Suhrkamp, 1999, pp. 95 y ss.

12 GÓMEZ-JARA, Fundamentos modernos de la culpabilidad empresarial, cit. no 5, pp. 315 y ss.; BACIGALUPO, La responsabilidad penal de las personas jurídicas, cit. nota $\mathrm{n}^{\circ}$ 5, pp. 365 y ss.; HETZER, Wolfgang, "Schuldlose Sanktionssubjekte. Unternehmenskriminalität und Verbandsstrafe", Wistra 1999, p. 367.

${ }^{13}$ FRENCH, "The Corporation as a Moral Person", cit. nota $n^{\circ} 4$, p. 146. Entre nosotros, retoma esta argumentación: ARTAZA, La empresa como sujeto de imputación de responsabilidad penal, cit. nota $\mathrm{n}^{\circ} 6$, pp. 194 y ss. Críticamente: VELASQUEZ, Manuel G., "Debunking Corporate Moral Responsibility”, 13 Bus. Ethics Q. (2003), pp. 531 y ss.; HASNAS, John, “The Centenary of a Mistake: One Hundred Years of Corporate Criminal Liability”, Am. Crim. L. Rev. 46 (2009), pp. 1330 y ss. Similar, PETTIT, Phillip, Una teoría de la libertad, Buenos Aires: Losada, 2006, p. 119, quien afirma que los colectivos integrados son sujetos "robóticos" a los que los individuos dan vida por medio de la suspensión de sus propios proyectos de 
Aquí la palabra "activation" es suficientemente ilustrativa de lo problemático del argumento: la culpabilidad colectiva sólo podría sostenerse disolviendo la individualidad, lo que supone caminar en sentido contrario al derecho penal, pues éste se basa en que respecto a determinados deberes personales básicos uno no puede renunciar a su responsabilidad a favor de una supuesta razón colectiva ${ }^{14}$. La conocida defensa de Eichmann no fue válida precisamente por eso, porque sus argumentos de "yo sólo ejecutaba órdenes" y "soy la víctima de un engaño" describen una situación de sumisión muy alejada de la realidad ${ }^{15}$. Además, si bien ello podría discutirse para el caso de los empleados subalternos, respecto a los directivos resulta particularmente absurdo, pues siendo ellos los que deciden en buena parte la política empresarial, y siendo la política empresarial la que "sometería" a los agentes individuales, habría que aceptar algo tan extraño como que los directivos se someten a sí mismos cuando actúan para la organización.

El segundo problema es de tipo lógico, y tiene que ver con el salto argumental que existe entre el nivel de la comunicación social -lo que "se dice" o "se piensa" en la sociedad- y el nivel de la imputación penal. Se dice que las organizaciones son sujetos penales porque habitualmente les atribuimos intenciones; sin embargo, también atribuimos intenciones a los niños, a sistemas informáticos, o al "derecho" mismo sin que por ello vayamos a considerarles sujetos penales ${ }^{16}$. También se fundamenta su culpabilidad en que las organizaciones son sujetos relevantes socio-económicamente, verdaderos agentes en la creación de "sentido social"" normativo", como si la capacidad de culpabilidad de un sujeto dependiese del modo en que es percibido en la interacción social. Resulta, al contrario, que el derecho penal no sólo no puede ser un mero reflejo del imaginario social, sino que muy a menudo debe servir de

cara a servir al punto de vista colectivo; y continúa: los colectivos se sirven "de la continua sumisión -aunque lo normal es que se trate de una sumisión voluntaria- de los individuos que los integran". Crítico con PETTIT: ORTIZ DE URBINA, Íñigo, "La responsabilidad penal de las personas jurídicas y su impacto en el derecho penal económico”, en: SILVA SÁNCHEZ, Jesús-María; MIRÓ LLINARES, Fernando (Dirs.), La teoría del delito en la práctica penal económica, Madrid: La Ley, 2013, p. 497.

${ }^{14}$ MAÑALICH, Juan Pablo, "Organización delictiva. Bases para su elaboración dogmática en el derecho penal chileno", R. Ch. D., Vol. 38, n 2 (2011), p. 299; JAKOBS, Günther, "Strafbarkeit juristischer Personen?", en: PRITTWITZ, Cornelius (hrgb.), Festschrift für Klaus Lüderssen, Baden-Baden: Nomos, 2002, p. 569. Sobre ello: JASPERS, Die Schuldfrage, cit. nota $\mathrm{n}^{\circ} 1$, pp. 38 y ss., quien destaca de qué modo el tratamiento de un colectivo como sujeto criminal implica simultánea y necesariamente la "disolución del hombre como individualidad".

${ }^{15}$ ARENDT, Eichmann en Jerusalén, cit. nota $\mathrm{n}^{\mathrm{o}}$ 1, pp. 245 y ss.; en relación al Estado, JASPERS, Die Schuldfrage, cit. nota $\mathrm{n}^{\mathrm{o}} 1, \mathrm{p} .51$.

${ }^{16}$ LÜBBE, Verantwortung in komplexen kulturellen Prozessen, cit. nota $\mathrm{n}^{\mathrm{o}}$ 11, p. 31: "No todo sujeto gramatical es como tal un sujeto de acción"; JAKOBS, "Strafbarkeit juristischer Personen?", cit. nota n 14, p. 561. Tal y como ha desarrollado ampliamente Paul RICOEUR (Sí mismo como otro, Madrid: Siglo XXI, 1996, Cap. III-IV) en su crítica al filósofo D. Davidson (en el que, por otra parte, se basa Peter French), la teoría de la acción es autónoma respecto a los enunciados lingüísticos, precisamente porque en la acción se manifiesta la "capacidad de iniciativa" de un agente, y éste ha de constituirse necesariamente como un ente diferenciado del mundo de las cosas, también del mundo del lenguaje. Críticamente, DAN-COHEN, Meir, "Sanctioning Corporations", J.L. \& Pol'y. no 19 (2010), 19, quien califica estos planteamientos de "holismo lingüistico".

17 GÓMEZ-JARA, Fundamentos modernos de la culpabilidad empresarial, cit. no 5, pp. 383 y ss.; KOHLHOFF, Christian, Kartellstrafrecht und Kollektivstrafe, Berlin: Duncker \& Humblot, 2003, pp. 302 y ss. 
CIGÜELA, Javier "Culpabilidad, identidad y organización colectiva".

límite y contrapeso frente al mismo; es decir, podría ser que en la comunicación se tuviera por responsable al padre por lo que ha hecho su hijo terrorista, o a un colectivo racial por lo que ha hecho uno de sus miembros, sin que ello deba tener un reflejo en una responsabilidad vicarial o una culpabilidad colectiva en el derecho penal.

\section{Culpabilidad e identidad en el sujeto colectivo}

Dicen Deleuze y Guattari que la comunicación versa sobre opiniones, y que sirve para crear "consenso" pero no "concepto" 18 . Así, si la posibilidad de una culpabilidad del sujeto colectivo no depende de comunicaciones sociales, la cuestión a determinar es de qué depende; la respuesta es, en mi opinión, que toda pregunta sobre la culpabilidad constituye una pregunta por la identidad del sujeto al que se quiere atribuir ${ }^{19}$. Así, el conjunto de requisitos que ha desarrollado la ciencia penal para referirse a la imputabilidad podrían reconducirse a una serie de facetas de la identidad del sujeto candidato, concretamente la temporalidad, la unidad, la capacidad cognitiva, la identidad ética y la política. La idea de fondo sería la siguiente: para que la atribución de culpabilidad a un sujeto sea racional es necesario, en primer lugar, que dicho sujeto tenga las capacidades que justificarían su estatuto como agente moral; y, en segundo lugar, que el sujeto culpable sea el mismo que el que cometió el delito. Sobre esa base, a continuación analizaré la identidad de la organización colectiva en relación a los requisitos de imputación penal, y para ello no sólo tendré en cuenta su identidad en sentido formal -su personalidad jurídica-, sino especialmente su identidad material, en cuanto «estado de cosas» o «estructura organizativa» que puede tener influencia propia en la actividad delictiva. En este caso la pregunta ha de ser: ¿tiene la organización las condiciones de identidad que justificarían la atribución de una culpabilidad?

\subsection{La identidad temporal de la persona jurídica: ¿continuidad biográfica de la empresa?}

La identidad temporal constituye un aspecto nuclear en la pregunta sobre la capacidad de culpabilidad de un sujeto, en el sentido de que ha de ser posible afirmar la continuidad

\footnotetext{
${ }^{18}$ DELEUZE, Gilles; GUATTARI, Félix, ¿Qué es la filosofía?, Barcelona: Anagrama, 1993, p. 13; más adelante (p. 33): "La comunicación siempre llega demasiado pronto o demasiado tarde, y la conversación siempre está de más cuando se trata de crear (J.C.: conceptos)".

${ }^{19}$ En el plano filosófico, la relación entre culpabilidad e identidad ha sido ampliamente explorada: RICOEUR, Paul, Finitud y culpabilidad, Madrid: Taurus, 1982, p. 20, para quien la culpabilidad supone la discordancia entre el "yo de los actos concretos" y el "yo primordial" que "permanece más allá de sus actos"; KANT, Inmanuel, Metaphysik der Sitten, Königsberg: Nicolovius, 1979, Einleitung, XI; HEIDEGGER, Martin, Sein und Zeit, Tübingen: Max Neiemeyer Verlag, 1967, §58; FOUCAULT, Michel, Wrong-Doing, Truth-Telling, Chicago: University of Chicago Press, 2014, p. 210; PETTIT, Una teoría de la libertad, cit. nota $\mathrm{n}^{\circ}$ 13, p. 118. En la ciencia penal: KAUFMANN, Arthur, Das Schuldprinzip. Eine strafrechtlichrechtsphilosophische Untersuchung, Heidelberg: Carl Winter Universitätsverlag, 1961, p. 201; SILVA SÁNCHEZ, Jesús-María, "Identidad en el tiempo y responsabilidad penal. El juicio «jurisdiccional» de imputación de responsabilidad entre agente y acusado", en: GARCÍA VALDÉS, Carlos et al (Eds.) Estudios penales en homenaje a Enrique Gimbernat, Tomo II, Madrid: Edisofer, 2008, pp. 661 y ss. En relación a la empresa: QUAID, Jennifer, "The assessment of Corporate Criminal Liability on the basis of Corporate Identity: An Analysis", Mc. Gill L. J. 43 (1998), 75; EIDAM, Gerd, Straftäter Unternehmen, München: Beck, 1997, pp. 104, 107; VON FREIER, Friedrich, Kritik der Verbandsstrafe, Berlin: Duncker \& Humblot, 1998, pp. 88 y ss., 115 y ss.
} 
biográfica del sujeto al que desea imponerse una pena ${ }^{20}$. La identidad temporal se manifiesta, en primer lugar, en la "capacidad de memoria", lo que permite al sujeto reconocerse como el mismo que fue o que hizo algo en el pasado; en segundo lugar, en la "capacidad de promesa", lo que proyecta al sujeto hacia el futuro, y le permite comprometerse a realizar algo, a cumplir un deber personal en adelante ${ }^{21}$. La relevancia penal de esta idea es clara: la pena tiene sentido sólo si el sujeto puede reconocerse en el presente como el mismo sujeto que delinquió en el pasado (de otro modo la pena aparecerá ante él como un mal irracional y arbitrario), del mismo modo que debe poder comprometerse hacia el futuro, asegurando el cumplimiento de sus deberes ${ }^{22}$. En relación a la culpabilidad colectiva, la cuestión es si es posible sostener que la organización a la que se impone una pena es la misma, en términos de continuidad biográfica, que aquella donde se produjo el defecto organizativo que se le debería imputar; si se puede reconocer como el sujeto que delinquió y que no cumplió su promesa de cumplimiento.

En ese sentido, es cierto que todo sujeto colectivo desarrolla cierta identidad a lo largo del tiempo: de todos ellos se puede hacer una narración que permita hilar la historia del sujeto en cuestión a lo largo de los diferentes momentos. Así, a pesar del cambio en sus miembros, McDonald's es reconocible como sujeto económico del que se narra una historia, en su caso principalmente gracias a su imagen de marca y a sus productos; del mismo modo que EEUU es reconocible a lo largo del tiempo como sujeto político, gracias a sus símbolos, su cultura y demás signos identificativos ${ }^{23}$. La cuestión es si esa identidad narrativa, que efectivamente existe, es suficiente para atribuir una culpabilidad al sujeto colectivo en el momento del proceso (t2) por lo que se hizo en el momento del hecho delictivo (t1). Se ha de tener en cuenta, además, que en la medida en que la culpabilidad penal lleva consigo cierto grado de reproche, no basta con que el sujeto entienda como razonable "hacerse cargo" de determinados eventos del pasado; es necesario, por el contrario, que el reproche recaiga en el mismo sujeto que delinquió, que ha de poder entender la pena como justa consecuencia de un comportamiento propio ${ }^{24}$.

Pues bien, ello no ocurre en las personas jurídicas: la razón es que todo lo que constituye su identidad material -sus órganos, su cultura o política empresarial, sus productos, etc.- está en permanente cambio, razón por la cual su continuidad biográfica no está internamente

\footnotetext{
${ }^{20}$ La idea de temporalidad como base de la identidad está ampliamente desarrollada en la teoría de la narratividad, especialmente en RICOEUR, Sí mismo como otro, cit. nota $\mathrm{n}^{\circ} 16$, pp. 141 y ss.; TAYLOR, Charles, Sources of the Self, Cambridge: Cambridge Univ. Press, 1992, p. 50: MEUTER, Norbert, Narrative Identität. Das Problem der personalen Identität im Anschluß an Ernst Tugendhat, Niklas Luhmann und Paul Ricoeur, Stuttgart: M\&P, 1993, pp. 124 y ss.; también SEARLE, John, The Construction of Social Reality, New York: Simon and Schuster 1995, pp. 134 y ss.; o desde una perspectiva psicológica, HÄUßER, Karl, Identitätpsichologie, Berlin: Springer-Verlag, 1995, p. 28.

${ }^{21}$ Sobre ello: ARENDT, The Human Condition, Chicago: University of Chicago Press, 1998, pp. 243 y ss.; RICOEUR, Sí mismo como otro, cit. nota $\mathrm{n}^{\circ}$ 16, p. 154.

${ }^{22}$ SILVA SÁNCHEZ, "Identidad en el tiempo y responsabilidad penal", cit. nota $n^{\circ} 19$, p. 676; HAUSER, Christian, Selbstbewußtsein und Personale Identität, Stuttgart: Friedrich Fromann Verlag, 1994, p. 104.

${ }^{23}$ Sobre la memoria colectiva: vid. BLUSTEIN, Jeffrey, Moral demands of memory, Cambridge: Cambridge University Press, 2008, pp. 185 y ss.

${ }^{24}$ Así: SILVA SÁNCHEZ, "Identidad en el tiempo y responsabilidad penal", cit. nota $\mathrm{n}^{\circ}$ 19, p. 676; JAKOBS, "Strafbarkeit juristischer Personen?", cit. nota n 14, p. 565.
} 
CIGÜELA, Javier "Culpabilidad, identidad y organización colectiva".

asegurada y es una cuestión de azar ${ }^{25}$. Y lo decisivo no es tanto que la identidad colectiva sea cambiante (la identidad del ser humano también lo es), como el hecho de que dichos cambios no son el producto de una elaboración propia sino que depende de la voluntad de terceros (sus administradores), quienes van configurando conjuntamente la identidad de la empresa a lo largo del tiempo. Así, es difícil hablar de continuidad en la empresa una vez hayan cambiado los administradores, los accionistas o gran parte de la plantilla, precisamente porque la empresa donde se cometió el delito no es ya «la misma» que la que debería recibir el reproche con posterioridad. Por ello, lo que un consejo de administración realice permanecerá como obra de sus integrantes en la esfera de organización de la empresa, pero no podrá serle reprochado a la empresa misma tiempo después: en primer lugar, porque la empresa por sí misma no es capaz de comprender el contenido comunicativo de la pena, no puede "recordar" que ella fue la que dio origen al hecho punible (ver 3.3); en segundo lugar, quienes lo hacen por ella, sus administradores, habrán con toda probabilidad cambiado, y quienes tengan que responder (como representantes) por aquél defecto organizativo serán sujetos distintos de los que lo generaron. El reproche mismo se convierte, por tanto, en un "mensaje sin aludidos".

Por razones de confianza social y seguridad jurídica, parece razonable que las empresas como colectivos con una identidad narrativa débil o dependiente- carguen con su pasado organizativo (también con las consecuencias por los delitos), y que la responsabilidad persista más allá de los cambios en su dirección; la cuestión es que ese cargar no tiene la forma de una culpabilidad penal, pues el sujeto colectivo al que se querría castigar ya no existe como sujeto identificable con el sujeto del pasado, y, como afirma Jakobs, "el conocimiento de tener que responder por la culpabilidad de otro y el conocimiento de tener que responder por la propia culpabilidad son dos cosas distintas"26.

\subsection{Problemas de identidad como unidad de acción}

Otra fuente de problemas para fundamentar la culpabilidad la encontramos en la exigencia de una identidad como "unidad de acción", concretamente en el hecho de que la organización no es un sujeto unitario sino un "meta-sujeto", esto es, un sujeto compuesto

\footnotetext{
25 Destacan problemas de continuidad en la empresa: WELLS, Celia, Corporations and Criminal Responsibility, Oxford: Clarendon Press, 1993, p. 93: "La responsabilidad penal sólo tiene sentido si la empresa retiene o bien su nombre o sus directores, pero una vez ello se ha perdido es difícil decir qué es lo que la compañía es"; VON FREIER, Kritik der Verbandsstrafe, cit. nota no 19, p. 115, 143; LÜDERSSEN, Klaus, "The Aggregative Model: Jenseits von Fiktionen und Surrogaten", en: KEMPF, Eberhard; LÜDERSSEN, Klaus; VOLK, Klaus (Eds.), Unternehmensstrafrecht, Berlin/Boston: De Gruyter, 2012, p. 99; JAKOBS, "Strafbarkeit juristischer Personen?", cit. nota no 14, p. 569; PÉREZ DEL VALLE, Carlos, Lecciones de Derecho Penal: Parte General, Madrid: Dykinson, 2016, §2.II.B; FEIJOO SÁNCHEZ, Bernardo, “Autorregulación y derecho penal de la Empresa: ¿Una cuestión de responsabilidad individual?", en: ARROYO JIMÉNEZ, Luis; NIETO MARTÍN, Adán (Dirs.), Autorregulación y sanciones, Valladolid: Lex Nova, 2008, pp. 218; SCHMITT-LEONARDY, Charlotte, Unternehmenskriminalität ohne Strafrecht?, Heidelberg: C.F. Müller, 2013, p. 448; ORTIZ DE URBINA, "La responsabilidad penal de las personas jurídicas", cit. nota $\mathrm{n}^{\circ} 13$, pp. 495 y ss. Seguramente esa es la razón por la que G.F.W. HEGEL (Grundlinien der Philosophie des Rechts, Frankfurt am Main: Suhrkamp, 2000, §279) había expresado que la persona jurídica o moral, "por muy concreta que sea en sí misma, tiene la personalidad sólo como momento, sólo de un modo abstracto; no ha alcanzado en ella la verdad de su existencia" (a excepción, según el filósofo alemán, del Estado).

${ }^{26}$ JAKOBS, “Strafbarkeit juristischer Personen?”, cit. nota no 14, p. 569.
} 
por diferentes sujetos autónomos. Por explicarlo etimológicamente: "in-dividuum" significa "lo que no se puede dividir" 27 , lo que caracteriza a la persona individual -que actúa siempre como "unidad de vida bio-psicológica" - en contraste con la colectiva, cuya constitución es siempre múltiple, compuesta y divisible en múltiples sujetos autoresponsables, a través de los cuales se manifiesta de cara al exterior -realiza contratos, presta servicios, etc.-. Precisamente en torno a esta problemática se sitúa la divergencia entre los dos grandes modelos de culpabilidad empresarial: el «modelo de culpabilidad por el hecho propio» describe la organización como un "todo" que se organiza a sí mismo, y el hecho de que sus actos se materialicen necesariamente a través de sus administradores queda reducido a un "dato naturalístico", penalmente irrelevante ${ }^{28}$; el «modelo de culpabilidad por transferencia», en cambio, reconoce el carácter compuesto de la organización, esto es, admite que el hecho antijurídico lo producen los administradores, sólo que bajo determinadas condiciones se imputa a la organización ${ }^{29}$.

Pues bien, como han dicho ya otros autores, esta distinción es ficticia: sólo existen «modelos de transferencia o imputación», más o menos refinados dogmáticamente ${ }^{30}$. La diferencia es sólo metodológica: en los «modelos de transferencia» la falta de identidad penal de la organización se compensa mediante imputaciones - de la acción o de la culpabilidad ajenas-, mientras que en los «modelos de culpabilidad propia» se compensa mediante ficciones o constructos -así, Gómez-Jara: “el sistema jurídico (...) necesita construir una serie de identidades a las cuales adscribir sus comunicaciones jurídicas"31-.

\footnotetext{
${ }^{27}$ Así reza la conocida cita de BOETHIUS, In Isagogen Porphyrii Commenta, 1906, p. 195 (Editionis secundae, liber II, 7). Un estudio semántico del concepto de "individuo": RICOEUR, Sí mismo como otro, cit. nota $\mathrm{n}^{\mathrm{o}} 16$, pp. 39 y ss.

${ }^{28}$ Proponen modelos de culpabilidad "propia", entre otros: HEINE, Die strafrechtliche Verantwortlichkeit von Unternehmen, cit. nota $\mathrm{n}^{\circ}$ 8, pp. 256 y ss.; LAMPE, "Systemunrecht und Unrechtssysteme", cit. nota $\mathrm{n}^{\circ} 1$, pp. 697, 707; BACIGALUPO, La responsabilidad penal de las personas jurídicas, cit. nota $\mathrm{n}^{\circ} 5$, pp. $351 \mathrm{y}$ ss.; GÓMEZ-JARA, Fundamentos modernos de la culpabilidad empresarial, cit. nº 5, pp. 310 y ss.; NIETO MARTÍN, Adán, La responsabilidad penal de las personas jurídicas: un modelo legislativo, Madrid: Iustel, 2008, pp. 145 y ss.

${ }^{29}$ Sostienen modelos de transferencia: SCHROTH, Hans-Jürgen, Unternehmen als Normadressaten und Sanktionssubjekte, Gießen: Brühlscher Verlag, 1993, p. 188; HIRSCH, "Strafrechtliche Verantwortlichkeit von Unternehmen", cit. nota $\mathrm{n}^{\mathrm{o}} 11$, pp. 285 ss.; EHRHARDT, Anne, Unternehmensdelinquenz und Unternehmensstrafe, Berlin: Duncker \& Humblot, 1994, pp. 177, 186 y ss.

${ }^{30}$ SILVA SÁNCHEZ, "La responsabilidad penal de las personas jurídicas y las consecuencias accesorias del art. 129 del Código penal", en: AA.VV., Derecho penal económico. Madrid: Consejo General del Poder judicial, 2001, pp. 328; MIR PUIG, Santiago, "Una tercera vía en materia de responsabilidad penal de las personas jurídicas", REDPC 06 (2004), p. 17; ROBLES PLANAS, Ricardo, "Pena y persona jurídica: crítica del artículo 31 bis CP (1)", Diario La Ley, no 7705 (2011), habla de "variante refinada"; FRISCH, Wolfgang, "Strafbarkeit juristischer Personen und Zurechnung", en: ZÖLLER, Mark; HILGER, Hans; KÜPER, Wilfried; ROXIN, Claus (Eds.), Gesamte Strafrechtwissenschaft in internationaler Dimension, Festschrift für Jürgen Wolter zum 70. Geburtstag am 7. September 2013, Berlin: Duncker \& Humblot, 2013, p. 368; GRACIA MARTÍN, Luis, "La serie "infracción-culpabilidad-sanción” desencadenada por individuos libres como síntesis jurídica indisoluble derivada de la idea y del concepto a priori del derecho", RECPC, 18-18 (2016), p. 36. Ya Hans KELSEN (Reine Rechtslehre, Österreichische Staatsdruckerei Wien, 1992, p. 189) había advertido que toda responsabilidad colectiva tiene en alguna medida la forma de una responsabilidad por hechos ajenos.

${ }^{31}$ GÓMEZ-JARA, Fundamentos modernos de la culpabilidad empresarial, cit. $\mathrm{n}^{\mathrm{o}}$ 5, pp. 288 y ss. (cursiva mía); EL MISMO, "Grundlagen des konstruktivistischen Unternehmensschuldbegriffs", ZStW 119 (2007), 290 y ss., donde define al sujeto del derecho como un "constructo del sistema penal" y como un "artefacto
} 
CIGÜELA, Javier "Culpabilidad, identidad y organización colectiva".

Sin embargo, estas ficciones rinden explicativamente como metáforas -como sucede con la culpabilidad colectiva misma ${ }^{32}$-, o a lo sumo en el ámbito sociológico o económico, donde puede considerarse a la empresa como un ser "auto-referencial" o "auto-organizado", que decide sus políticas económicas y el rumbo de su actividad ${ }^{33}$. Las cosas son distintas en lo que al derecho penal respecta, pues cuando se trata de orientarse normativamente, la empresa constituye un ser claramente hetero-organizado, que no puede decidirse a favor del derecho en contra de lo que digan sus administradores. La razón tiene que ver con la distinción lógica entre acciones primarias y secundarias: los actos colectivos, por pertenecer a personas jurídicas que requieren representación, son siempre acciones secundarias o derivadas, en la medida en que tienen su origen en acciones primarias de otros agentes (individuales o entes colegiados), que realizan una prestación a la persona representada. Desde un punto de vista lógico, las acciones secundarias, en tanto derivan de las acciones primarias, no pueden ser equivalentes a ellas ${ }^{34}$.

Por esa razón, la conocida metáfora de Gierke no es cierta: es erróneo afirmar que los administradores son como una extremidad del cuerpo empresarial, pues si así fuese aquéllos deberían dejar de considerarse como personas autónomas para el derecho penal (una extremidad no responde) ${ }^{35}$. Tampoco lo es la de Luhmann, cuando afirma que los

semático" del sistema jurídico. La idea está presente ya en BOTTKE, Wilfried, Assoziationsprävention. Zur heutigen Diskussion der Strafzwecke, Berlin: Duncker \& Humblot, 1995, p. 62; BACIGALUPO, La responsabilidad penal de las personas jurídicas, cit. nota $\mathrm{n}^{\circ} 5$, pp. 104 y ss., y tiene su origen inmediato en la teoría de sistemas: LUHMANN, Niklas, Soziologische Aufklärung 6. Die Soziologie und der Mensch. $1^{\text {a }}$ ed. Darmstadt: Westdeutscher Verlag, 1995, pp. 148 y ss. Lo que ocurre en los modelos de culpabilidad propia, especialmente los de corte sistémico-normativista, es que las carencias de la organización quedan diluidas o disimuladas por elevación del discurso, que se sitúa en un meta-nivel ("Meta-ebene") sumamente abstracto, basado en conceptos como "organización", "autopoiesis", "competencia", "comunicación”, etc., de contenido abierto e indeterminado. Así, Wilfired Bottke afirma en relación a la organización: Así es en la medida en que se afirma, por ejemplo, que "las normas jurídicas no fungen como un medio de conducción inmediata desde el exterior", sino que "estimulan la autoconducción y la conformación de una correspondiente actitud subjetiva"; todo lo cual, sin embargo, se afirma sin aclarar cómo es posible para el colectivo la "conformación de una actitud subjetiva" si no es a través de sus miembros individuales, esto es, por medio de una "heteroconducción" ("hetero-steuerung"). Críticos con el lenguaje constructivista, entre otras cosas, por su distancia respecto de la racionalidad normativa: HABERMAS, Jurgen, Faktizität und Geltung, Frankfurt am Main: Suhrkamp, 1992, pp. 69 y ss.; SACHER, Mariana, "Systemtheorie und Strafrecht. Kritik der rollenbezogenen Zurechnungslehre", ZStW 118 (2006), 579; SCHÜNEMANN, Bernd, "Strafrechtliche Sanktionen gegen Wirtschaftsunternehmen?", en: SIEBER, Ulrich; DANNECKER, Gerhard (Hrgb.), Festschrift für zum Klaus Tiedemann zum 70. Geburtstag, Köln: Karl Heymann Verlag, 2008, p. 437, de quien tomo la expresión de "Meta-ebene"; VON FREIER, Kritik der Verbandsstrafe, cit. nota no 19, p. 114.

${ }^{32}$ El propio KELSEN, Reine Rechtslehre, cit. nota. no 30, p. 186, las llama "metáforas antropomórficas"; también, ARENDT, Hannah, "Responsabilidad colectiva", Claves de Razón Práctica, no 95 (1999), pp. 8 y ss. ${ }_{33}$ vid. SCHMITT-LEONARDY, Unternehmenskriminalität ohne Strafrecht?, cit. nota ${ }^{\circ} 25$, pp. 134 y ss.

${ }^{34}$ En ese sentido: SCHÜNEMANN, Festschrift für zum Klaus Tiedemann, cit. nota no 31, p. 431; SCHROTH, Unternehmen als Normadressaten und Sanktionssubjekte, cit. $\mathrm{n}^{\circ} 29$, pp. 177 y ss., quien habla de la capacidad acción de la organización como acción derivada o secundaria. Lo discutible es que se pueda hablar de una culpabilidad propia basada en una capacidad que reside en un sujeto ajeno. También, críticamente: VON FREIER, Kritik der Verbandsstrafe, cit. nota $\mathrm{n}^{\circ}$ 19, pp. 98 y ss.; GRACIA MARTÍN, "La serie "infracciónculpabilidad-sanción'”, cit. nota no 30 , pp. 36 y ss.

${ }^{35}$ GIERKE, Otto von, Das Wesen der menschlichen Verbände, Berlin: Buchdruckerei von G. Schade, 1902, pp. 9 y ss. Críticamente: JAKOBS, "Strafbarkeit juristischer Personen?", cit. nota $\mathrm{n}^{\circ}$ 14, p. 567; VON FREIER, Kritik der Verbandsstrafe, cit. nota $\mathrm{n}^{\circ}$ 19, pp. 162 y ss.; NEUMANN, Ulfried, "Strafrechtliche Verantwortlichkeit von Verbänden -rechtstheoretische prolegomena-", en: KEMPF, Eberhard; 
administradores son "entorno" para la empresa: no sólo no son entorno, sino que son la condición misma que posibilita la relación de la empresa con su entorno ${ }^{36}$. En esa línea, no parece plausible reducir a un "mero dato naturalístico" el hecho de que la empresa sólo pueda actuar por iniciativa de sus administradores, pues el mismo fenómeno de la representación es puramente jurídico y no natural ${ }^{37}$, tan relevante como que lo que los administradores hacen por la empresa puede constituir para ellos mismos un delito ${ }^{38}$.

Por tanto, si resulta que la persona jurídica no tiene capacidad de iniciativa propia y por tanto no puede infringir personalmente un deber ${ }^{39}$, entonces es necesario transferir el hecho y la culpabilidad desde el órgano a la propia organización; sin embargo, culpabilidad y transferencia son términos contradictorios, pues la culpabilidad es personalísima y lo que es personalísimo no se puede transferir; además, resulta que lo que se transfiere a la organización debe serle descargado al órgano, pues contra un único hecho (el del órgano) no se pueden duplicar dos culpabilidades; pero con ello llegaríamos precisamente a lo que se pretendía evitar, la irresponsabilidad organizada de quienes actúan en el interior de la organización ${ }^{40}$.

LÜDERSSEN, Klaus; VOLK, Klaus (Eds.), Unternehmensstrafrecht, Berlin/Boston: De Gruyter, 2012 , p. 16.

36 LUHMANN, Organisation und Entscheidung, cit. nota $\mathrm{n}^{\mathrm{o}} 5$, pp. 80 y ss.; GÓMEZ-JARA, "Autoorganización empresarial y autorresponsabilidad empresarial. Hacia una verdadera responsabilidad penal de las personas jurídicas”, RECPC no 08-05 (2006), p. 594. Críticamente: SCHÜNEMANN, "Strafrechtliche Sanktionen gegen Wirtschaftsunternehmen?", cit. nota $\mathrm{n}^{\mathrm{o}}$ 31, p. 440. Sin embargo, el argumento de Luhmann es en sí mismo problemático, pues a menudo él mismo presupone que los individuos realizan operaciones para la empresa que, desde un punto de vista conceptual, no podrían hacer desde su entorno. Así, por ejemplo, en relación a la memoria: "la organización permanece dependiente de la memoria individual de los participantes, cosa que a menudo conduce a informaciones muy diversas", y por ello "las posibilidades de crear una memoria propia de la organización son limitadas" (p. 86).

${ }^{37}$ Así, la conocida explicación de HOBBES, Thomas, Leviathan, Or the Matter, Forme and Power of a Common-Wealth Ecclesiasticall and Civill, New Haven: Yale University Press, 2010, pp. 98 y ss.

${ }^{38}$ Sobre ello: JAKOBS, "Strafbarkeit juristischer Personen?", cit. nota n 14, pp. 562 y s. Además, separar de ese modo los administradores de la empresa - convirtiéndoles en su "entorno"- impediría tematizar precisamente la exigencia que se hace a los administradores para que implementen un compliance, pues éste funciona sólo sobre el presupuesto de que un determinado cambio originado desde la dirección puede reconducir la situación colectiva hacia la normalidad jurídica, como también de que los sistemas tienen una realidad objetiva que puede ser, aunque sea limitadamente, "diseñada y modelada" por quienes los administran. En ese sentido: KREINER RAMIREZ, Mary, "The Science Fiction of Corporate Criminal Liability: Containing the Machine through the Corporate Death Penalty", Arz. L. Rev., vol. 47 (2005), p. 965.

${ }^{39}$ A la organización le falta la "capacidad de iniciativa", esto es, el poder de originar de modo espontáneo cambios en el mundo, para lo cual se exige inmediatez entre la voluntad decisoria y su manifestación en el mundo exterior, vid. RICOEUR, Sí mismo como otro, cit. nota ${ }^{\circ} 16$, pp. 123 y ss. Ello no está presente en la organización, pues entre la supuesta voluntad colectiva y su manifestación social existe siempre un cúmulo de personas individuales interpuestas, cuya actuación no puede reducirse a una aplicación mecánica de aquélla al menos mientras queramos seguir considerando que los individuos son seres autónomos y autorresponsables también cuando actúan para la organización-.

${ }^{40}$ Estas ideas se corresponden con la conocida crítica de JAKOBS, "Strafbarkeit juristischer Personen?”, cit. nota $\mathrm{n}^{\mathrm{0}} 14$, p. 564 y ss., retomada entre muchos otros por VAN WEEZEL, Alex, "Contra la responsabilidad penal de las personas jurídicas”, Pol. Crim., Vol. 5, nº 9 (2010), pp. 131 y ss.; y anticipada ya por ALWART, Heiner, "Strafrechtliche Haftung des Unternehmens - von Unternehmenstäter zum Täterunternehmen", ZStW 105 (1993), p. 757. 
CIGÜELA, Javier "Culpabilidad, identidad y organización colectiva".

Parece evidente aquí que la persona colectiva no genera ella misma el defecto organizativo que debería imputársele, sino que lo generan sus sucesivos miembros de modo progresivo, acumulativo y a menudo difuso. La cuestión de si lo anterior puede producir alguna consecuencia jurídica - distinta de la culpabilidad- para la propia organización ha sido tratada en otro lugar ${ }^{41}$; lo que parece claro, a tenor de lo aquí expuesto, es que si ella misma no genera el hecho delictivo su responsabilidad no se puede predicar por un hecho propio.

\subsection{Problemas de identidad como orientación cognitiva}

La culpabilidad penal está relacionada con otra dimensión de la identidad, relacionada con la capacidad cognitiva, y que en el caso del sujeto individual denominamos conciencia -o cuando el objeto de conocimiento es uno mismo, "auto-conciencia" ${ }^{42}$. En relación al derecho penal, esta cuestión aparece en varios momentos: el sujeto en cuestión debe poder aprehender el contenido comunicativo de la norma, del mismo modo que, ulteriormente, debe poder comprender el contenido comunicativo del castigo; además, debe poder identificarse como el sujeto que cometió el delito que merece un castigo. Lo que se busca no es un pensamiento o un sentimiento conforme o favorable a las normas ${ }^{43}$, pero sí al menos la capacidad para manifestar un posicionamiento frente a ella, y sólo puede posicionarse quien puede comprender y comportarse conforme a dicha comprensión.

Varios han sido los intentos de justificar un equivalente funcional de la conciencia en las organizaciones colectivas. Desde posiciones funcionalistas, se ha afirmado que la propia complejidad de la organización -su carácter "autopoiético"- proporciona las razones para equiparar su identidad subjetiva con la del individuo ${ }^{44}$. Del mismo modo que el individuo se forma una imagen de sí mismo y del mundo a través de la memoria y el conocimiento cerebral, la organización hace lo propio mediante la memoria y el conocimiento organizativo, los cuales permiten a la organización planificar mediante políticas y decisiones colectivas lo que va a hacer en el futuro, y en el futuro entender lo que ocurre

${ }^{41}$ CIGÜELA SOLA, La culpabilidad colectiva en el derecho penal. Crítica y propuesta de una responsabilidad estructural de la empresa, cit. nota $\mathrm{n}^{\circ} 3$, Parte III; EL MISMO, InDret, 1/2015, cit. nota $\mathrm{n}^{\circ} 3$.

42 Junto con la idea de autonomía, la "conciencia" ha sido el otro gran concepto sobre el que se ha asentado la identidad a lo largo de la modernidad, y con ella la responsabilidad subjetiva. Así, especialmente: LOCKE, John, An Essay Concerning Human Understanding, Oxford: 1979 Libro II, Cap. XXVII, §9; HEGEL, Grundlinien der Philosophie des Rechts, cit. nota $\mathrm{n}^{\circ}$ 25, §129. Sobre ello: LOTTER, Maria-Sibylla, Scham, Schuld und Verantwortung, Frankfurt am Main: Suhrkamp, 2012., pp. 64 y ss.; PAWLIK, Michael, Das Unrecht des Bürgers, Tübingen: Mohr Siebeck, 2012, pp. 141 y ss.; JAKOBS, "Strafbarkeit juristischer Personen?", cit. nota n ${ }^{\circ}$ 14, p. 569.

${ }^{43}$ Claramente, HEGEL, Grundlinien der Philosophie des Rechts, cit. nota $\mathrm{n}^{\circ} 25, \S 2$, p. 137, para quien la racionalidad formal del derecho -en términos contemporáneos: su validez-no puede depender de los hechos de conciencia, ni de los sentimientos ni de cualquier otro saber singular. Dicho en otros términos: no se trata de que el derecho pueda penetrar en las conciencias, moldear su contenido material y conformarlas; se trata simplemente de reconocer que las normas jurídicas sólo pueden dirigirse a un destinatario que pueda comprender lo que ellas exigen. A partir de esa capacidad de comprensión el sujeto se puede determinar en favor o en contra de la norma; sin ella el sujeto no puede posicionarse frente al derecho, y por ello no puede lesionar la norma de modo culpable. En esa línea, HABERMAS, Faktizität und Geltung, cit. nota nº 31, pp. $143,153$.

${ }^{44}$ LUHMANN, Organisation und Entscheidung, cit. nota $\mathrm{n}^{\circ}$ 5, pp. 39 y ss.; TEUBNER, "Enterprise Corporatism", cit. nota $\mathrm{n}^{\circ}$ 5; GÓMEZ-JARA, Fundamentos modernos de la culpabilidad empresarial, cit. nota $\mathrm{n}^{\circ}$ 5, pp. 150 y ss.; KOHLHOFF, Kartellstrafrecht und Kollektivstrafe, cit. nota n ${ }^{\circ}$ 17, p. 309. 
como el producto de sus decisiones del pasado. Como las decisiones remiten a otras decisiones, y éstas a planificaciones, y éstas al contenido de la memoria, con el tiempo se va generando la recursividad o reflexividad suficiente para entender a la empresa como un sujeto que "sabe lo que hace", no reductible, en palabras de Bottke, a un "destino ciego" 45 .

Sin embargo, a pesar del intento de presentar todo este proceso como propio de la organización, lo cierto es que tanto la memoria, como las decisiones o el conocimiento organizativo son fenómenos que emergen de sus integrantes, quienes recogen, interpretan y actualizan "el pasado organizativo" desde su propia subjetividad, y muy a menudo en su propio interés (por ejemplo, ocultando algún dato que pueda perjudicar su posición, o que le pueda incriminar $)^{46}$. En la medida en que no es la organización misma quien recuerda y conoce, su identidad subjetiva no está internamente asegurada, no descansa en una capacidad cognitiva estable. Con ello queda a disposición de la prestación de sus miembros $\mathrm{y}$, por tanto, del azar, pues muy probablemente el sujeto que recoge en determinado momento una información relevante no esté en el momento en el que debe ser recordada (por ejemplo, en el proceso penal) ${ }^{47}$. La memoria y el conocimiento organizativos son, por tanto, fenómenos complejos, que tienen una dimensión estructural -lo que se recoge es la vida del sujeto colectivo y según unos objetivos organizativos- y una dimensión individual -quienes lo recogen son siempre sujetos individuales que añaden su propia complejidad al proceso memorístico-; en esa medida, una identidad basada en una memoria dependiente ha de reputarse necesariamente como una identidad dependiente, esto es, no autónoma.

A ello se le suma que, en realidad, la capacidad de culpabilidad no depende de una medida de complejidad: un "loco" o un "algoritmo informático" presentan idéntica o mayor complejidad que quien está en plenas facultades mentales, y sin embargo los excluimos del reproche de culpabilidad. La razón es que no basta con ser un ente complejo, sino que además se requiere la capacidad de comprender el sentido de los actos propios, y de actuar conforme a esa comprensión. Sin embargo, esa comprensión sólo es posible en la organización a través de su órgano, de nuevo de un modo mediato, y por ello el conocimiento que tenga la organización de sí misma, o el que tenga respecto a sus deberes penales, será un conocimiento "disgregado y descentralizado" en diversos individuos, particularmente sus directivos y administradores. Ello vuelve a presentar una importante dificultad, pues una culpabilidad no puede predicarse como propia y a la vez fundarse en una capacidad de conocimiento ajena; al tiempo que culpabilizar a la empresa supondría dirigir un reproche a un sujeto que no tuvo, por sí mismo, la oportunidad de comprender la norma y, por tanto, de comunicar una posición personal frente a ella ${ }^{48}$.

\footnotetext{
${ }^{45}$ BOTTKE, "Standortvorteil Wirtschaftskriminalrecht", cit. nota $n^{\circ} 5$, p. 249. Sobre los procesos de decisión en la organización: LUHMANN, Organisation und Entscheidung, cit. nota n ${ }^{\circ}$ 5, pp. 222 y ss., 256 y ss.

${ }^{46}$ LUHMANN, Organisation und Entscheidung, cit. nota n ${ }^{\circ}$ 5, pp. 154, 669; LAMPE, "Systemunrecht und Unrechtssysteme", cit. nota $\mathrm{n}^{\circ}$ 1, p. 669; PETTIT, Una teoría de la libertad, cit. nota $\mathrm{n}^{\circ}$ 13, p. 119.

${ }^{47}$ Así, JAKOBS, "Strafbarkeit juristischer Personen?", cit. nota no 14, p. 569.

${ }^{48}$ En sentido parecido, VON FREIER, Kritik der Verbandsstrafe, cit. nota $\mathrm{n}^{\text {o }}$ 19, pp. 29, 136; KÖHLER, Michael, Strafrecht AT, Berlín, Heidelberg, Nueva York: Springer, 1997, p. 562; NIETO MARTÍN, La responsabilidad penal de las personas jurídicas, cit. $\mathrm{n}^{\circ} 11$, p. 70. También LUHMANN, Organisation und Entscheidung, cit. nota $\mathrm{n}^{\circ} 5$, pp. Cap. VII, $\S 7$, reconoce algo similar cuando afirma que las organizaciones mismas no pueden percibir, y que sus "rutinas cognitivas" emergen de la praxis de decisión del sistema, la cual, en sentido estricto, tiene lugar en el infra-nivel de la interacción entre miembros, y no en el supra-nivel
} 
CIGÜELA, Javier "Culpabilidad, identidad y organización colectiva".

\subsection{Problemas de identidad ética}

Se ha discutido mucho acerca de si el reproche penal debe integrar algún contenido éticomoral $^{49}$. Precisamente la vinculación entre personalidad ética y culpabilidad penal, propia del pensamiento de Hegel, supuso durante largo tiempo el principal impedimento para sostener la punibilidad de las personas jurídicas, a las que se excluía de la moralidad ${ }^{50}$. En diferente medida y con argumentos diversos, la mayor parte de autores favorables a la culpabilidad colectiva han intentado fundamentar una personalidad ética en las organizaciones: no se trataría tanto de una personalidad basada en la libertad o en la conciencia moral - como ha sucedido tradicionalmente con el individuo ${ }^{51}$, sino de otra basada en la competencia social, esto es, en la capacidad de las organizaciones de ser centros de imputación, de responsabilizarse ético-jurídicamente de sus acciones/comunicaciones ${ }^{52}$. Así, lo que defienden es que las organizaciones van formando un ethos o un "estado de cosas organizativo", que sería éticamente relevante en la medida en que suponga una contradicción del derecho ${ }^{53}$. Se destaca, además, la importancia que

de la comunicación.

${ }^{49}$ En sentido contrario, de modo paradigmático: KORIATH, Heinz, Grundlagen strafrechtlicher Zurechnung, Berlin: Duncker \& Humblot, 1994, pp. 29 y ss.; HOYER, Andreas, Strafrechtdogmatik nach Armin Kaufmann, Berlin: Duncker \& Humblot, 1997, p. 46 y ss.

${ }^{50}$ Sobre ello: BINDER, Julius, Das Problem der juristischen Persönlichkeit, Leipzig: Deichert, 1907, p. 13. La tesis de Hegel fue desarrollada, en el sentido de excluir a las personas jurídicas del derecho penal, entre otros, por: KÖSTLIN, Reinhold, System des deutschen Strafrechts, 1855 (Neudruck 1978), pp. 121 y ss.; recientemente, con idéntico argumento, VON FREIER, Kritik der Verbandsstrafe, cit. nota n ${ }^{\circ} 19$, pp. 126 y ss.; STRATENWERTH, Günther, "Strafrechtliche Unternehmenshaftung?", en: GEPPERT, Klaus et al (Eds.), Festschrift für Rudolf Schmitt zum 70. Geburtstag. Tübingen: Mohr, 1992, p. 305.

51 Así, ya desde ARISTÓTELES, Ética a Nicómaco, Madrid: Alianza, 2001, §1110a, se asocia toda responsabilidad a lo que tiene su origen en la libre voluntad y a la capacidad de deliberación; si bien es con HEGEL, Grundlinien der Philosophie des Rechts, cit. nota n ${ }^{\circ} 25, \S 129$ y ss., cuando ello llega a su máxima expresión. Sobre ello: PÉREZ DEL VALLE, Carlos, Estudios de filosofía política y del derecho penal, Madrid: Dykinson, 2007, pp. 77 y ss.

${ }^{52}$ En estos planteamientos se opta no tanto por vaciar la pena de contenido ético-moral, sino más bien por minimizarlo y suavizarlo: así sucede, por ejemplo, con quienes sostienen una vertiente social de la culpabilidad, que substituye el reproche ético-individual por uno de carácter ético-social, referido no tanto a un código de justo/injusto sino más bien a una comparación respecto a una "empresa media": con matices, DANNECKER, Gerhard, "Zur Notwendigkeit der Einführung kriminalrechtlicher Sanktionen gegen Verbände", GA 2001, p. 112; LAMPE, "Systemunrecht und Unrechtssysteme", cit. nota no 1, p. 724; SCHROTH, Unternehmen als Normadressaten und Sanktionssubjekte, cit. $\mathrm{n}^{\circ}$ 29, p. 200. Otra versión es el concepto funcional de culpabilidad por organización, que debilita o prescinde de la noción de reproche y explica la sanción como la respuesta necesaria a una "defraudación de expectativas": de nuevo con matices BOTTKE, "Standortvorteil Wirtschaftskriminalrecht", cit. nota $\mathrm{n}^{\mathbf{0}}$ 5, p. 253; BACIGALUPO, La responsabilidad penal de las personas jurídicas, cit. nota ${ }^{\circ}$ 5, pp. 218 y ss.; GÓMEZ-JARA, Fundamentos modernos de la culpabilidad empresarial, cit. nota $\mathrm{n}^{\circ}$ 5, pp. 175, 258 y ss.

${ }^{53}$ Sobre el "ethos empresarial": BUCY, Pamela H., "Corporate Ethos: a Standard for Imposing Corporate Criminal Liability”, Minn. L. Rev. 75 (1991), pp. 1095 y ss.; ARTAZA, La empresa como sujeto de imputación de responsabilidad penal, cit. nota $\mathrm{n}^{\mathrm{o}}$ 6, pp. 251 y ss. Numerosos autores sostienen, de hecho, modelos de culpabilidad empresarial basados específicamente en el carácter o filosofía criminógena de la organización: LAMPE, "Systemunrecht und Unrechtssysteme", cit. n 1, pp. 728 y ss., EL MISMO, Strafphilosophie, Köln: Carl Heymanns, 1999, p. 74; HEINE, Die strafrechtliche Verantwortlichkeit von Unternehmen, cit. nota $\mathrm{n}^{\circ}$ 8, pp. 266 y ss.; NIETO MARTÍN, La responsabilidad penal de las personas jurídicas, cit. $\mathrm{n}^{\circ} 11$, pp. 127 y ss.; MAÑALICH, “Organización delictiva”, cit. nota n ${ }^{\circ} 14$, pp. 303 y ss. Críticamente: VON FREIER, Kritik der Verbandsstrafe, cit. nota no 19, pp. 142 y ss.; ROBLES PLANAS, ¿Delitos de personas jurídicas? A propósito de la ley Austriaca de la responsabilidad de agrupaciones por 
tiene en el tráfico económico la "reputación" o el "prestigio" de las empresas, lo que justificaría que en esos contextos se les atribuye algo así como un "carácter social", que a su vez puede ser objeto de calificación ética ("banco ético", "empresa ecológica", "organización perversa", etc.) ${ }^{54}$.

La primera crítica a estos planteamientos es bien conocida: la empresa es un ente cuyo código operativo no es el de justo/injusto sino el de beneficio/pérdida, donde el derecho aparece siempre en forma de "coste", traducido a una lógica mercantilista" 55 . La pena sería, para la empresa, un "precio" asociado al comportamiento defectuoso, y no un llamamiento al cumplimiento de sus deberes ético-jurídicos ${ }^{56}$. En mi opinión, ninguna de las dos tesis es del todo precisa. La empresa no es, como en ocasiones se ha dicho, un "zombie moral" que sólo pueda integrar entre sus objetivos el beneficio económico ${ }^{57}$; como tampoco se puede afirmar, al contrario, que constituya un sujeto con autonomía moral, capaz de recibir un reproche por lo que ocurre en su interior. Es decir, la actividad de una empresa tiene un significado ético para la sociedad, y por ello una empresa que dedica parte de sus beneficios a labores sociales estará mejorando el estatus ético de su sociedad, mientras que una empresa esclavista lo estará empeorando. Ahora bien, el reproche asociado a la culpabilidad penal no constituye una calificación social/general de un acontecimiento determinado, sino que supone un juicio personalísimo, individualizador; y cuando el derecho ha de juzgar el hecho antijurídico que desearía reprocharse a la empresa -la organización defectuosa o la filosofía criminógena- se encuentra con que son individuos concretos, determinables o no, quienes han tomado las decisiones éticamente loables o reprobables. Por ejemplo, si se produce un acuerdo entre administradores de una empresa donde 7 votan a favor de distribuir un aceite potencialmente cancerígeno, y 3 votan en contra, el reproche sólo puede dirigirse contra esos 7 administradores, pero no contra un colectivo de personas donde cada uno ha realizado un comportamiento de significación ética diversa.

hechos delictivos", InDret 2/2006, pp. 10 y ss., quienes destacan, entre otras cosas, que el derecho penal no puede contar entre sus objetivos el de moldear caracteres, ni el de los individuos ni el de las empresas. En mi opinión, el principal inconveniente es que el carácter criminógeno que desarrolle la persona jurídica no será una elaboración propia que merezca un reproche, sino a lo sumo un fenómeno que emerge espontáneamente de las interacciones que se producen en su interior, lo que implica, a su vez, que no puede reprochársele a la empresa como propio.

${ }^{54}$ Sobre el "carácter social": LAMPE, "Systemunrecht und Unrechtssysteme", cit. nota no 1, p. 723. Así, BOTTKE, "Standortvorteil Wirtschaftskriminalrecht", cit. nota n' 5, p. 253.

55 JESCHECK, Hans H., "Die Strafrechtliche Verantwortlichkeit von Personenverbände", ZStW 65 (1953), p. 213; TEUBNER, "The Invisible Cupola: From Casual to Collective Attribution in Ecological Liability", Card. L. Rev. 15 (1994), 451; COFFEE JR., John, "Does "Unlawful” Mean "Criminal”?: Reflections on the Disappearing Tort/crime Distinction in American Law", B.U.L. Rev. 71 (1991), p. 228; MIR PUIG, "Una tercera vía en materia de responsabilidad penal", cit. nota $\mathrm{n}^{\circ} 30$, p. 13; ROBLES PLANAS, "Pena y persona jurídica: crítica del artículo 31 bis CP (1)", cit. nota no 30; LAMPE, "Systemunrecht und Unrechtssysteme", cit. $\mathrm{n}^{\text {o }}$ 1, P. 699, aunque luego trata de compatibilizarlo con exigencias ético-sociales; SCHÜNEMANN, Festschrift für zum Klaus Tiedemann, cit. nota $\mathrm{n}^{\circ}$ 31, pp. 429, 438; SCHMITT-LEONARDY, Unternehmenskriminalität ohne Strafrecht?, cit. nota $\mathrm{n}^{\circ} 25$, pp. 333, 460, entre muchísimos otros.

${ }^{56}$ Ver NEUMANN, Ulfried, "Das Corpus Juris im Streit um europäisches Strafrecht”, en: HUBER, Barbara (Ed.), Das Corpus Juris als Grundlage eines Europäischen Strafrechts, Freiburg: Iuscrim, 2000, pp. 80 y ss.; KAHAN, Dan M.,"What do Alternative Sanctions Mean”, U.Ch.L.Rev. 63 (1996), pp. 621 y ss.

57 La expression "zombie moral" es utilizada descriptivamente por SCHMITT-LEONARDY, Unternehmenskriminalität ohne Strafrecht?, cit. nota $\mathrm{n}^{\circ} 25, \mathrm{p} .431$. 
CIGÜELA, Javier "Culpabilidad, identidad y organización colectiva".

En este punto se observan, por tanto, las dos razones fundamentales por las que toda semántica del reproche -sea éste ético, moral, jurídico o todo a la vez- entra en conflicto con la identidad de la empresa: en primer lugar, la infracción de deberes ético-jurídicos exige una capacidad de iniciativa de la que la organización carece, pues el modo en que una empresa mejora o empeora el mundo se explica como un cúmulo de acciones individuales organizadas pero diversas, y no como una acción colectiva unitaria; en segundo lugar, partiendo de que en el interior de las organizaciones se producen siempre comportamientos de significado ético diverso, el problema es que la culpabilidad colectiva supone siempre una generalización, un juicio moral superficial incompatible con el principio fundamental del derecho penal moderno, a saber: la individualización de la culpabilidad ${ }^{58}$.

\subsection{Problemas de identidad política: la corporación como un no-igual}

El concepto de culpabilidad está relacionado, por último y especialmente en sus últimas evoluciones dogmáticas ${ }^{59}$, con el aspecto político de la identidad, esto es, con la capacidad del sujeto de posicionarse a favor o en contra de aquellas normas cuya infracción se le imputa. Partiendo de una tradición que va desde Kant (principio de auto-legislación) hasta Habermas (principio del discurso) ${ }^{60}$, el Estado sólo podría exigir el cumplimiento de las obligaciones penales a quienes ha asegurado el ejercicio de sus derechos correlativos, precisamente aquellos que asociamos a la ciudadanía política, esto es, la participación en el debate público y el derecho al sufragio. La pregunta es, entonces, si las empresas y el resto de organizaciones son auténticos sujetos políticos, si participan de modo relevante en la conformación de aquellas normas cuya infracción debería reprochárseles penalmente.

Pues bien, en lo que va desde Hobbes hasta Rawls, pasando por Kant, el concepto de ciudadanía política está restringido a las personas individuales: las organizaciones sociales serían el producto del pacto social, y no sus sujetos ${ }^{61}$. Más complicado es el juicio en lo

\footnotetext{
${ }^{58}$ ARENDT, Claves de Razón Práctica, cit. nota no 32 , pp. 8 y ss.

${ }^{59}$ GÜNTHER, Klaus, Schuld und kommunkative Freiheit, Frankfurt am Main: Vittorio Klostermann, 2005, p. 250; KINDHÄUSER, Urs, "Rechtstreue als Schuldkategorie", ZStW 107 (1995); así como la obra conjunta, KINDHÄUSER, Urs; MAÑALICH, Juan Pablo, Pena y culpabilidad en el Estado democrático de Derecho, Buenos Aires: BdF, 2011; MARTÍN LORENZO, María, La exculpación penal: Bases para una atribución legítima de responsabilidad penal, Valencia: Tirant, 2009, 274 y ss.

${ }^{60}$ KANT, Immanuel, Grundlegung zur Metaphysik der Sitten, Stuttgart: Phillip Reclam, 1984, pp. 82 y ss; HABERMAS, Faktizität und Geltung, cit. nota no 31 , pp. 138, 152 y ss.

${ }^{61}$ Así, HOBBES, Leviathan, cit. nota ${ }^{\circ} 5, \S 16.82$, en referencia a las corporaciones: "such things cannot be Personated, before there be some state of Civill Government"; SPINOZA, Baruch, Tratado político, Madrid: Alianza, 2013, Cap. III. §1; KANT, Metaphysik der Sitten, cit. nota nº 19, § 46, pp. 165 y ss., quien reconoce, no obstante, un tipo de "ciudadanía pasiva" para sujetos (mujeres, menores de edad, etc.) que no tienen "autonomía política" ni el derecho a votar -según Kant, "sólo la capacidad de votar cualifica al ciudadano "; este tipo de «ciudadanía pasiva» se predica de ellos porque "esa dependencia con respecto a la voluntad de otros y esa desigualdad no se oponen en modo alguno a su libertad e igualdad como hombres, que juntos constituyen un pueblo". Atendiendo a esta afirmación la inclusión de la persona jurídica como ciudadano pasivo es problemática, pues ni son sujetos libres ni iguales a los hombres en el sentido kantiano de estos términos. El concepto de ciudadanía incompleta está ya desarrollado en ARISTÓTELES, Política, Madrid: Alianza, 2009, §1275a. El caso de John RAWLS (Teoría de la justicia, México: Fondo de Cultura Económica, 1995) es más discutible: por un lado, considera explícitamente como sujetos del pacto no solamente a los individuos sino también a las asociaciones ("Estados, iglesias y otras corporaciones"); sin embargo, en otro lugar ("Justice as reciprocity" en: GOROVITZ, Samuel (Ed.), John Stuart Mill,
} 


\section{Polít. crim. Vol. 12, № 24 (Diciembre 2017), Art. 7, pp. 908-931. [http://www.politicacriminal.cl/Vol_12/n_24/Vol12N24A7.pdf]}

relativo a la teoría del discurso de Habermas y su traslación al derecho penal por Günther. En lo que respecta a Habermas, a pesar de la apertura de los presupuestos comunicativos de los que parte ${ }^{62}$, en su planteamiento las normas jurídicas "están dirigidas a individuos": "sólo se les supone y exige la capacidad de tomar decisiones racionales con arreglo a fines, es decir, libertad de arbitrio"63; formulación que parece excluir a las personas jurídicas, al menos como destinatarias directas. Llegamos, en cualquier caso, al problemático concepto de "libertad", que en los planteamientos comunicativos está en gran medida vacío de contenido. Así, para Günther, la libertad comunicativa no está conectada a la libertad de acción o de voluntad, tampoco a cuestiones ontológicas o metafísicas, sino que depende del "trasfondo comunicativo" de la sociedad ${ }^{64}$. Ello implica que su atribución a la organización dependerá de cómo la sociedad se entienda a sí misma y de cómo entienda a las organizaciones ${ }^{65}$.

Más allá de que aquí vuelven a aparecer los problemas ya tratados de remitir el contenido de los conceptos a la comunicación o al entendimiento social ${ }^{66}$, lo cierto es que incluso en el planteamiento de Günther parece difícil integrar a las organizaciones como "personas libres y deliberativas". En primer lugar, porque el autor hace depender la capacidad de actuar de la posesión de "capacidades y disposiciones psíquicas y fisiológicas"67 de las que

Utilitarianism, Indianapolis: Bobbs-Merrill, 1971, pp. 244 y ss.) considera que "existe una prioridad lógica" en relación a los individuos, de modo que es posible "analizar las acciones de las llamadas personas artificiales como construcciones lógicas de acciones de personas humanas", lo que debería descartar la consideración de éstas como personas políticamente autónomas. Esta opinión es compartida por FRENCH, "The Corporation as a Moral Person", cit. nota $\mathrm{n}^{\circ}$ 4, pp. 134 y ss., quien interpreta que el pacto social en Rawls excluye a las organizaciones en la medida en que describe a los sujetos del mismo como seres racionales que operan conforme la lógica de la psicología moral.

${ }^{62}$ BACIGALUPO, Enrique, Compliance y Derecho Penal, Navarra: Aranzadi, 2011, pp. 93 y ss., interpreta que el paradigma comunicativo - donde integra a Habermas y Luhmann- presenta una alternativa plausible al modelo clásico de "racionalidad instrumental", y en él la identificación entre pena y voluntad natural podría abandonarse a favor de una teoría de la prevención general positiva aperturista respecto a los sujetos colectivos.

${ }^{63}$ HABERMAS, Faktizität und Geltung, cit. nota no 31, p. 144; PRITTWITZ, Cornelius; GÜNTHER, Klaus, "Individuelle und Kollektive Verantwortung im Strafrecht", en: HERZOG, Felix; NEUMANN, Ulfrid (Eds.), Festschrift für Winfried Hassemer, Heidelberg: C.F. Müller Verlag, 2010, p. 343: "las normas jurídicas se dirigen finalmente siempre a individuos".

${ }^{64}$ GÜNTHER, Schuld und kommunikative Freiheit, cit. nota no 59, pp. 2, 246 y ss.

${ }^{65}$ Claramente: PRITTWITZ/GÜNTHER, "Individuelle und Kollektive Verantwortung im Strafrecht", cit. nota $\mathrm{n}^{\circ} 63$, p. 343, donde sostienen que en determinados ámbitos -entre ellos la criminalidad empresarial- la exclusión de la responsabilidad colectiva supondría llevar la tentación neo-individualista demasiado lejos, si bien no concretan ni el tipo de responsabilidad ni el estatuto jurídico-penal que correspondería a los sujetos colectivos.

${ }^{66}$ En el caso de Günther existe la siguiente contradicción: por un lado, afirma que la comunidad no puede asignar arbitrariamente roles de autor a sujetos como si fuesen marionetas ("puppets"), ya que el reconocimiento comunicativo como autor presupone la libertad comunicativa (GÜNTHER, Klaus, "Communicative Freedom, Communicative Power, and Jurisgenesis", Card.L.Rev. 17 (1996), pp. 245 y ss.); pero resulta que si esa la libertad es un mero producto de la comunicación, en ningún caso sirve de límite a una atribución que tiene su origen también en la comunicación (también crítico con esa circularidad: SÁNCHEZ-OSTIZ, Pablo, "Recensión a Klaus Günther, Schuld un Kommunikative Freiheit", InDret 3 (2006), p. 7; y si esa libertad está más allá de la comunicación, vuelve a ser ontológica o metafísica, lo cual se negó de antemano al ser calificada de "ficción" (GÜNTHER, Schuld und kommunikative Freiheit, cit. nota n” 59, p. 2)

${ }^{67}$ GÜNTHER, Schuld und kommunikative Freiheit, cit. nota no 59, pp. 246 y ss. 
CIGÜELA, Javier "Culpabilidad, identidad y organización colectiva".

las organizaciones no disponen. En segundo lugar, porque dicho estatus está conectado a la capacidad para la toma de posición crítica frente a las manifestaciones propias y ajenas, así como frente a las normas ${ }^{68}$, lo que en las organizaciones sólo puede tener lugar, de nuevo, de modo mediato - por ej. la persona jurídica no puede "distanciarse" de lo que manifiesten sus administradores respecto a una política económica estatal-. Por último, la "persona deliberativa" debe ser reconocida socialmente como "origen de sus propias manifestaciones y acciones", y como partícipe del reconocimiento mutuo de los ciudadanos como sujetos libres e iguales. Sin embargo, las organizaciones no son por sí mismas capaces de originación, pues el rastro de sus manifestaciones llevará siempre hasta la actuación conjunta de otras personas deliberativas -de nuevo, a las acciones primarias de su órgano-Y lo que es más importante, no forman parte (ni deberían hacerlo) de la comunidad de sujetos libres e iguales: no sólo carecen del derecho al sufragio -el único que, al menos formalmente, asegura la igualdad ${ }^{69}$, sino que, además, la ciudadanía corporativa implicaría otorgarles un estatus socio-político que no les corresponde -la organización puede ser disuelta por el mero acuerdo de sus socios, ergo no es un sujeto libre ni igual a ellos- ${ }^{70}$.

En definitiva, en el dudoso caso de que la culpabilidad penal dependiera exclusivamente de condicionamientos políticos ${ }^{71}$, el estatus de las organizaciones no podría considerarse en modo alguno equiparable al de los individuos: en lo político la organización es un no-igual respecto a los sujetos individuales, y en esa medida la ciudadanía no puede ser una vía por la que justificar su capacidad de culpabilidad.

\section{Conclusión}

Los modelos de culpabilidad colectiva aciertan en gran medida en la identificación de la organización como ente que "añade algo" a la subjetividad y disposición individual de sus miembros. Mi discrepancia está, sin embargo, en que la influencia que la organización pueda tener en la comisión de delitos - ese "algo" que añade, por mucho que sea- no es integrable en la semántica de la culpabilidad, y ello por dos motivos: la organización no tiene la capacidad de originar de modo autónomo el hecho organizativo que debería imputársele, pues su defecto de organización o su filosofía criminógena son fenómenos que emergen progresivamente de la actuación acumulativa, conjunta y difusa de sus miembros (presentes y pasados), y no de decisiones propias; en segundo lugar, la organización desarrolla sólo como prestación de sus miembros -esto es: de modo no autónomo y débillas condiciones de identidad (temporal, unitaria, cognitiva, ética y política) que deberían justificar su estatuto de agente penal y su aptitud para el reproche de culpabilidad. En pocas palabras, aquello que la organización "es" -su filosofía o cultura corporativa- y aquello que

\footnotetext{
${ }^{68}$ GÜNTHER, Schuld und kommunikative Freiheit, cit. nota n ${ }^{\circ}$ 59, p. 255.

${ }^{69}$ De nuevo KANT, Metaphysik der Sitten, cit. nota ${ }^{\circ} 19, \S 46$.

${ }^{70}$ En ese sentido: VON FREIER, Kritik der Verbandsstrafe, cit. nota $\mathrm{n}^{\circ}$ 19, p.114; MAÑALICH, "Organización delictiva", cit. nota $\mathrm{n}^{\circ}$ 14, pp. 300 y ss.; JAKOBS, "Strafbarkeit juristischer Personen?", cit. nota $\mathrm{n}^{\circ}$ 14, p. 562; SCHMITT-LEONARDY, Unternehmenskriminalität ohne Strafrecht?, cit. nota $\mathrm{n}^{\circ}$ 25, pp. 448 y ss.: "Una participación tal de la empresa en los procesos democráticos como sujeto y ciudadano ni existe ni tan siquiera sería justificable de lege ferenda".

${ }^{71}$ Crítico con una legitimación puramente democrática de la pena: PAWLIK, "Selbstgesetzgebung der Regierten': Glanz und Elend einer Leigitimationsfigur", Recht und Politik, ARSP Beiheift 93 (2004), pp. 115 y ss.
} 
Polít. crim. Vol. 12, No 24 (Diciembre 2017), Art. 7, pp. 908-931.

[http://www.politicacriminal.cl/Vol_12/n_24/Vol12N24A7.pdf]

"hace" - su correcta o incorrecta organización- depende de otros, y no es posible hablar de una culpabilidad propia fundada en prestaciones que la organización recibe de terceros.

La conclusión es que la articulación de una respuesta jurídica - penal o de otro tipo- frente a las personas jurídicas no puede realizarse mediante el concepto de culpabilidad sin que éste pierda su contenido característico ${ }^{72}$, lo que no parece deseable para un discurso penal que está basado, ya sea en sus fundamentos o en sus límites, en dicha noción. Pero la culpabilidad no es la única forma de responsabilidad conocida por el derecho, y por ello la dogmática jurídica debe dedicar sus esfuerzos, tal y como se viene haciendo ya ${ }^{73}$, a construir un paradigma y una dogmática específicos para unas personas, jurídicas y colectivas, cuya identidad específica exige un marco conceptual diverso al de la culpabilidad. Por supuesto, las diferencias con respecto a la dogmática penal individual serán a menudo pequeñas, incluso de matiz. Pero es precisamente esa riqueza de matices, de distinciones y de niveles, lo que ha caracterizado a la dogmática penal frente a otras formas de pensar el derecho penal, y por ello resulta preferible enriquecer el discurso para pensar lo distinto como distinto, que simplificarlo en conceptos vacíos para pensarlo como igual $^{74}$.

\footnotetext{
${ }^{72}$ Por todos, recientemente: GRACIA MARTÍN, "La serie "infracción-culpabilidad-sanción”", cit. nota nº 30.

${ }^{73}$ Por supuesto, lo que se deba proponer aprovechará en gran medida las propuestas de teoría del delito de sus partidarios, pero no tendrá por qué ser coincidente, en la medida en que las diferencias en el fundamento conducirán necesariamente a diferencias en el nivel de la imputación. Propuestas recientes en ese sentido, hablando de "atribución" en vez de "imputación": GOENA VIVES, Beatriz, La atenuación de la responsabilidad penal de las personas jurídicas. Situación tras la reforma del Código Penal, Madrid: Marcial Pons, 2017; por mi parte, CIGÜELA SOLA, La culpabilidad colectiva en el derecho penal. Crítica y propuesta de una responsabilidad estructural de la empresa, cit. nota $\mathrm{n}^{\mathrm{o}} 3$, Parte III; EL MISMO, InDret, $1 / 2015$, cit. nota $\mathrm{n}^{\mathrm{o}} 3$.

${ }^{74}$ No en vano, para G.W.F. HEGEL (Phänomenologie des Geistes, Bamberg y Würzburg: J. A. Goebhardt, 1807, Prólogo, p. 37) "la tarea de distinguir es la energía y el trabajo del entendimiento... su poder absoluto" (“die Tätigkeit des Scheidens ist die Kraft und Arbeit des Verstandes, ... der Absoluten Macht”).
} 
CIGÜELA, Javier "Culpabilidad, identidad y organización colectiva".

\section{BIBLIOGRAFÍA}

ALWART, Heiner, "Strafrechtliche Haftung des Unternehmens - von Unternehmenstäter zum Täterunternehmen", ZStW 105 (1993), pp. 768 y ss.

ARENDT, Hannah, The Human Condition, Chicago: University of Chicago Press, 1998. , "Responsabilidad colectiva", Claves de Razón Práctica, no 95, 1999, pp. 8 y ss. , Eichmann en Jerusalén, Barcelona: DeBolsillo, 2010.

ARISTÓTELES, Ética a Nicómaco, Madrid: Alianza, 2001. , Politica, Madrid: Alianza, 2009.

ARTAZA, Osvaldo, La empresa como sujeto de imputación de responsabilidad penal. Fundamento y límites, Madrid: Marcial Pons, 2013.

BACIGALUPO, Enrique, Compliance y Derecho Penal, Navarra: Aranzadi, 2011.

BACIGALUPO, Silvina, La responsabilidad penal de las personas jurídicas, Barcelona: Bosch, 1998.

BINDER, Julius, Das Problem der juristischen Persönlichkeit, Leipzig: Deichert, 1907.

BLUSTEIN, Jeffrey, Moral demands of memory, Cambridge: Cambridge University Press, 2008.

BOETHIUS, In Isagogen Porphyrii Commenta, 1906 (Editionis secundae, liber II, 7).

BOTTKE, Wilfried, Assoziationsprävention. Zur heutigen Diskussion der Strafzwecke, Berlin: Duncker \& Humblot, 1995

"Standortvorteil Wirtschaftskriminalrecht: Müssen Unternehmen "strafmündig" werden? Bemerkungen zum Stand des Wirtschaftskriminalrechts inder Bundesrepublik Deutschland”, Wistra 1997, pp. 241 y ss.

BUCY, Pamela H., "Corporate Ethos: a Standard for Imposing Corporate Criminal Liability”, Minn. L. Rev. 75 (1991), p. 1095 y ss.

CIGÜELA SOLA, Javier, La culpabilidad colectiva en el derecho penal. Crítica y propuesta de una responsabilidad estructural de la empresa, Madrid: Marcial Pons, 2015.

, "El injusto estructural de la organización: aproximación al fundamento de la sanción a la persona jurídica", InDret 1/2015.

COFFEE JR., John, "Does "Unlawful" Mean "Criminal"?: Reflections on the Disappearing Tort/crime Distinction in American Law", B.U.L. Rev. 71 (1991), pp. 193 y ss.

COLVIN, Eric, "Corporate Personality and Criminal Liability", Criminal Law Forum 6 (1995).

DAN-COHEN, Meir, "Sanctioning Corporations", J.L. \& Pol'y. no 19 (2010), pp. 15 y ss.

DANNECKER, Gerhard, "Zur Notwendigkeit der Einführung kriminalrechtlicher Sanktionen gegen Verbände", GA 2001, pp. 101 y ss.

DELEUZE, Gilles; GUATTARI, Félix, ¿Qué es la filosofía?, Barcelona: Anagrama, 1993.

EHRHARDT, Anne, Unternehmensdelinquenz und Unternehmensstrafe, Berlin: Duncker \& Humblot, 1994.

EIDAM, Gerd, Straftäter Unternehmen, München: Beck, 1997.

FEIJOO SÁNCHEZ, Bernardo, "Autorregulación y derecho penal de la Empresa: ¿Una cuestión de responsabilidad individual?", en: ARROYO JIMÉNEZ, Luis; NIETO MARTÍN, Adán (Dirs.), Autorregulación y sanciones, Valladolid: Lex Nova, 2008, pp. 200 y ss. 
Polít. crim. Vol. 12, No 24 (Diciembre 2017), Art. 7, pp. 908-931.

[http://www.politicacriminal.cl/Vol_12/n_24/Vol12N24A7.pdf]

FOUCAULT, Michel, Wrong-Doing, Truth-Telling, Chicago: University of Chicago Press, 2014.

FRENCH, Peter A., "The Corporation as a Moral Person”, en: MAY, Larry; HOFFMAN, Stacy (Eds.), Collective Responsibility. Five decades of debate in theoretical and applied ethics, Maryland: Rowman \& Littlefield, 1991, pp. 133 y ss.

"Integrity, Intentions, And Corporations", Am. Bus. L. J., 34 (1996), pp. 141 y Ss.

FRISCH, Wofgang, "Strafbarkeit juristischer Personen und Zurechnung”, en: ZÖLLER, Mark; HILGER, Hans; KÜPER, Wilfried; ROXIN, Claus (Eds.), Gesamte Strafrechtwissenschaft in internationaler Dimension, Festschrift für Jürgen Wolter zum 70. Geburtstag am 7. September 2013, Berlin: Duncker \& Humblot, 2013, pp. 349 y ss.

GIERKE, Otto von, Das Wesen der menschlichen Verbände, Berlin: Buchdruckerei von G. Schade, 1902.

GOENA VIVES, Beatriz, La atenuación de la responsabilidad penal de las personas jurídicas. Situación tras la reforma del Código Penal, Madrid: Marcial Pons, 2017.

GÓMEZ-JARA, Carlos, "Autoorganización empresarial y autorresponsabilidad empresarial. Hacia una verdadera responsabilidad penal de las personas jurídicas", $R E C P C \mathrm{n}^{\circ} 08-05$ (2006).

, "Grundlagen des konstruktivistischen Unternehmensschuldbegriffs", ZStW 119 (2007), 290 y ss.

, Fundamentos modernos de la culpabilidad empresarial, Lima: Ara, 2009.

GRACIA MARTÍN, Luis, "La serie "infracción-culpabilidad-sanción” desencadenada por individuos libres como síntesis jurídica indisoluble derivada de la idea y del concepto a priori del derecho", RECPC, 18-18 (2016).

GÜNTHER, Klaus, "Communicative Freedom, Communicative Power, and Jurisgenesis", Card.L.Rev. 17 (1996), pp. 245 y ss.

, Schuld und kommunkative Freiheit, Frankfurt am Main: Vittorio Klostermann, 2005.

HABERMAS, Jürgen, Faktizität und Geltung, Frankfurt am Main: Suhrkamp, 1992.

HASNAS, John, "The Centenary of a Mistake: One Hundred Years of Corporate Criminal Liability", Am. Crim. L. Rev. 46 (2009), pp. 1330 y ss.

HAUSER, Christian, Selbstbewußtsein und Personale Identität, Stuttgart: Friedrich Fromann Verlag, 1994.

HÄUßER, Karl, Identitätpsichologie, Berlin: Springer-Verlag, 1995.

HEGEL, Georg W. F., Phänomenologie des Geistes, Bamberg y Würzburg: J. A. Goebhardt, 1807.

2000.

HEIDEGGER, Martin, Sein und Zeit, Tübingen: Max Neiemeyer Verlag, 1967.

HEINE, Günther, Die strafrechtliche Verantwortlichkeit von Unternehmen. Von individuellen Fehlverhalten zu kollektiven Fehlentwicklungen insbesondere bei Großrisiken. Baden-Baden: Nomos, 1995.

HETZER, Wolfgang, "Schuldlose Sanktionssubjekte. Unternehmenskriminalität und Verbandsstrafe", Wistra 1999, pp. 361 y ss. 
CIGÜELA, Javier "Culpabilidad, identidad y organización colectiva".

HIRSCH, Hans Joaquim, “Strafrechtliche Verantwortlichkeit von Unternehmen”, ZStW 107 (1995), pp. 1099 y ss.

HOBBES, Thomas, Leviathan, Or the Matter, Forme and Power of a Common-Wealth Ecclesiasticall and Civill, New Haven: Yale University Press, 2010.

HOYER, Andreas, Strafrechtdogmatik nach Armin Kaufmann, Berlin: Duncker \& Humblot, 1997.

JÄGER, Herbert, Makrokriminalität, Frankfurt am Main: Suhrkamp Verlag, 1989.

JAKOBS, Günther, "Strafbarkeit juristischer Personen?", en: PRITTWITZ, Cornelius (hrgb.), Festschrift für Klaus Lüderssen, Baden-Baden: Nomos, 2002, pp. 559 y ss.

JASPERS, Karl, Die Schuldfrage, Heidelberg: Lambert Schneider, 1946.

JESCHECK, Hans H., "Die Strafrechtliche Verantwortlichkeit von Personenverbände", ZStW 65 (1953), pp. 539 y ss.

JURKIEWICZ, Carole L. (Ed.), The Foundations of Organizational Evil, New York: M.E. Sharpe, 2012.

KAHAN, Dan M., "What do Alternative Sanctions Mean”, U.Ch.L.Rev. 63 (1996), pp. 621 y ss.

KANT, Inmanuel, Metaphysik der Sitten, Königsberg: Nicolovius, 1979.

, Grundlegung zur Metaphysik der Sitten, Stuttgart: Phillip Reclam, 1984.

KAUFMANN, Arthur, Das Schuldprinzip. Eine strafrechtlich-rechtsphilosophische Untersuchung, Heidelberg: Carl Winter Universitätsverlag, 1961.

KELSEN, Hans, Reine Rechtslehre, Österreichische Staatsdruckerei Wien, 1992 (ed. 1960).

KINDHÄUSER, Urs, “Rechtstreue als Schuldkategorie”, ZStW 107 (1995), pp. 701 y ss.

KINDHÄUSER, Urs; MAÑALICH, Juan Pablo, Pena y culpabilidad en el Estado democrático de Derecho, Buenos Aires: BdF, 2011.

KOHLHOFF, Christian, Kartellstrafrecht und Kollektivstrafe, Berlin: Duncker \& Humblot, 2003.

KORIATH, Heinz, Grundlagen strafrechtlicher Zurechnung, Berlin: Duncker \& Humblot, 1994.

KÖHLER, Michael, Strafrecht AT, Berlin, Heidelberg, Nueva York: Springer, 1997.

KÖSTLIN, Reinhold, System des deutschen Strafrechts, 1855 (Neudruck 1978).

KREINER RAMIREZ, Mary, "The Science Fiction of Corporate Criminal Liability: Containing the Machine through the Corporate Death Penalty", Arz. L. Rev., vol. 47 (2005), pp. 953 y ss.

LAMPE, Hans Joachim, “Systemunrecht und Unrechtssysteme”, ZStW 106 (1994), pp. 683 y ss.

, Strafphilosophie, Köln: Carl Heymanns, 1999.

LOCKE, John, An Essay Concerning Human Understanding, Oxford: 1979.

LOTTER, Maria-Sibylla, Scham, Schuld und Verantwortung, Frankfurt am Main: Suhrkamp, 2012.

LUHMANN, Niklas, Soziologische Aufklärung 6. Die Soziologie und der Mensch. 1ª ed., Darmstadt: Westdeutscher Verlag, 1995.

, Organisation und Entscheidung, Berlin: Springer-Verlag, 2011.

LÜBBE, Weyma, Verantwortung in komplexen kulturellen Prozessen, Freiburg/München: Verlag Karl Alber, 1998.

LÜDERSSEN, Klaus, "The Aggregative Model: Jenseits von Fiktionen und Surrogaten", en: KEMPF, Eberhard; LÜDERSSEN, Klaus; VOLK, Klaus (Eds.), Unternehmensstrafrecht, Berlin/Boston: De Gruyter, 2012, pp. 79 y ss. 
Polít. crim. Vol. 12, No 24 (Diciembre 2017), Art. 7, pp. 908-931.

[http://www.politicacriminal.cl/Vol_12/n_24/Vol12N24A7.pdf]

MAÑALICH, Juan Pablo, “Organización delictiva. Bases para su elaboración dogmática en el derecho penal chileno", $R$. Ch. D., Vol. 38, no 2 (2011), pp. 279 y ss.

MARTÍN LORENZO, María, La exculpación penal: Bases para una atribución legítima de responsabilidad penal, Valencia: Tirant, 2009.

MEUTER, Norbert, Narrative Identität. Das Problem der personalen Identität im Anschluß an Ernst Tugendhat, Niklas Luhmann und Paul Ricoeur, Stuttgart: M\&P, 1993.

MIR PUIG, Santiago, "Una tercera vía en materia de responsabilidad penal de las personas jurídicas”, REDPC 06 (2004).

NEUHÄUSER, Christian, Unternehmen als moralische Akteure, Frankfurt am Main: Suhrkamp, 1999.

NEUMANN, Ulfried, "Das Corpus Juris im Streit um europäisches Strafrecht", en: HUBER, Barbara (Ed.), Das Corpus Juris als Grundlage eines Europäischen Strafrechts, Freiburg: Iuscrim, 2000, pp. 67 y ss.

"Strafrechtliche Verantwortlichkeit von Verbänden -rechtstheoretische prolegomena”, en: KEMPF, Eberhard; LÜDERSSEN, Klaus; VOLK, Klaus (Eds.), Unternehmensstrafrecht, Berlin/Boston: De Gruyter, 2012, pp. 13 y ss.

NIETO MARTÍN, Adán, La responsabilidad penal de las personas jurídicas: un modelo legislativo, Madrid: Iustel, 2008.

ORTIZ DE URBINA, Íñigo, "La responsabilidad penal de las personas jurídicas y su impacto en el derecho penal económico", en: SILVA SÁNCHEZ, Jesús-María; MIRÓ LLINARES, Fernando (Dirs.), La teoría del delito en la práctica penal económica, Madrid: La Ley, 2013, pp. 457 y ss.

OSTERMEYER, Helmut, "Kollektivschuld im Strafrecht", ZRP, Heft 4/1971, pp. 76 y ss.

PAWLIK, Michael, "'Selbstgesetzgebung der Regierten': Glanz und Elend einer Leigitimationsfigur", Recht und Politik, ARSP Beiheift 93, 2004, pp. 115 y ss. , Das Unrecht des Bürgers, Tübingen: Mohr Siebeck, 2012.

PÉREZ DEL VALLE, Carlos, Lecciones de Derecho Penal: Parte General, Madrid: Dykinson, 2016. , Estudios de filosofía política y del derecho penal, Madrid: Dykinson, 2007.

PETTIT, Phillip, Una teoría de la libertad, Losada, 2006. "The reality of group agents", en: MANTZAVINOS, Chrysostomos (Ed.), Philosophy of the Social Sciences, Philosophical Theory and Scientific Practice. Cambridge: Cambridge University Press, 2009, pp. 67 y ss.

PRITTWITZ, Cornelius; GÜNTHER, Klaus, "Individuelle und Kollektive Verantwortung im Strafrecht", en: HERZOG, Felix; NEUMANN, Ulfrid (Eds.), Festschrift für Winfried Hassemer, Heidelberg: C.F. Müller Verlag, 2010, pp. 331 y ss.

QUAID, Jennifer, "The assessment of Corporate Criminal Liability on the basis of Corporate Identity: An Analysis", Mc. Gill L. J. 43 (1998), pp. 67 y ss.

RAWLS, John, "Justice as reciprocity" en: GOROVITZ, Samuel (Ed.), John Stuart Mill, Utilitarianism, Indianapolis: Bobbs-Merrill, 1971, pp. 244 y ss.

, Teoría de la justicia, México: Fondo de Cultura Económica, 1995.

RICOEUR, Paul, Sí mismo como otro, Madrid: Siglo XXI, 1996.

, Finitud y culpabilidad, Madrid: Taurus, 1982.

ROBLES PLANAS, Ricardo, “¿Delitos de personas jurídicas? A propósito de la ley Austriaca de la responsabilidad de agrupaciones por hechos delictivos", InDret 2/2006. 
CIGÜELA, Javier "Culpabilidad, identidad y organización colectiva”.

, "Pena y persona jurídica: crítica del artículo 31 bis CP (1)”, Diario La Ley, no 7705 (2011).

ROTH, Andreas, Kollektive Gewalt und Strafrecht, Berlin: Erich Schmidt Verlag, 1989.

ROTHENPIELER, Friedrich Wilhelm, Der Gedanke einer Kollektivschuld in juristischer Sicht, Berlin: Duncker \& Humblot, 1982.

ROTSCH, Thomas, "Unternehmen, Umwelt und Strafrecht- Ätiologie einer Misere (Teil 2)", Wistra 9 (1999), pp. 370 y ss.

SACHER, Mariana, "Systemtheorie und Strafrecht. Kritik der rollenbezogenen Zurechnungslehre", ZStW 118 (2006), pp. 574 y ss.

SÁNCHEZ-OSTIZ, Pablo, "Recensión a Klaus Günther, Schuld un Kommunikative Freiheit", InDret 3 (2006).

SCHMITT-LEONARDY, Charlotte, Unternehmenskriminalität ohne Strafrecht?, Heidelberg: C.F. Müller, 2013.

SCHROTH, Hans-Jürgen, Unternehmen als Normadressaten und Sanktionssubjekte, Gießen: Brühlscher Verlag, 1993.

SCHÜNEMANN, Bernd, "Strafrechtliche Sanktionen gegen Wirtschaftsunternehmen?", en: SIEBER, Ulrich; DANNECKER, Gerhard (Hrgb.), Festschrift für zum Klaus Tiedemann zum 70. Geburtstag, Köln: Karl Heymann Verlag, 2008, pp. 429 y ss.

SEARLE, John, The Construction of Social Reality, New York: Simon and Schuster, 1995.

SILVA SÁNCHEZ, Jesús-María, "Identidad en el tiempo y responsabilidad penal. El juicio «jurisdiccional» de imputación de responsabilidad entre agente y acusado", en: GARCÍA VALDÉS, Carlos et al (Eds.), Estudios penales en homenaje a Enrique Gimbernat, Tomo II, Madrid: Edisofer, 2008, pp. 661 y ss.

, "La responsabilidad penal de las personas jurídicas y las consecuencias accesorias del art. 129 del Código penal”, en: AA.VV., Derecho penal económico. Madrid: Consejo General del Poder judicial, 2001, pp. 307 y ss.

SPINOZA, Baruch, Tratado político, Madrid: Alianza, 2013.

STRATENWERTH, Günther, "Strafrechtliche Unternehmenshaftung?", en: GEPPERT, Klaus et al (Eds.), Festschrift für Rudolf Schmitt zum 70. Geburtstag. Tübingen: Mohr, 1992, pp. 295 y ss.

TAYLOR, Charles, Sources of the Self, Cambridge: Cambridge University Press, 1992.

TEUBNER, Günther, "Enterprise Corporatism. New Industrial Policy and the "Essence" of the Legal Person", Am. J. Comp. L. 36 (1988), pp. 130 y ss.

, "The Invisible Cupola: From Casual to Collective Attribution in Ecological Liability", Card. L. Rev. 15 (1994), pp. 429 y ss.

VELASQUEZ, Manuel G., "Debunking Corporate Moral Responsibility", Bus. Ethics Q. 13 (2003), pp. 531 y ss.

VAN WEEZEL, Alex, "Contra la responsabilidad penal de las personas jurídicas", Pol. Crim., Vol. 5, no 9 (2010).

VON FREIER, Friedrich, Kritik der Verbandsstrafe, Berlin: Duncker \& Humblot, 1998.

WELLS, Celia, Corporations and Criminal Responsibility, Oxford: Clarendon Press, 1993. 